\title{
Delivery of LLKKK18 loaded into self-assembling hyaluronic acid nanogel for tuberculosis treatment
}

\author{
João P. Silva ${ }^{\mathrm{a}, *}$, Carine Gonçalves b,c ${ }^{\text {, }}$ César Costa a ${ }^{\text {, Jeremy Sousa }}{ }^{\text {b,c }}$, Rita Silva-Gomes ${ }^{\text {b,c }}$, António G. Castro ${ }^{\text {b,c }}$, \\ Jorge Pedrosa ${ }^{\text {b,c }}$, Rui Appelberg ${ }^{\mathrm{d}}$, F. Miguel Gama ${ }^{\mathrm{a}, *}$ \\ a CEB - Centre of Biological Engineering, University of Minho, Campus de Gualtar, Braga 4710-057, Portugal \\ ${ }^{\mathrm{b}}$ Life and Health Sciences Research Institute (ICVS), School of Health Sciences, University of Minho, Braga, Portugal \\ c ICVS/3B's-PT Government Associate Laboratory, Braga/Guimarães, Portugal \\ d Department of Immunophysiology, University of Porto, 4050-313 Porto, Portugal
}

\section{A R T I C L E I N F O}

\section{Article history:}

Received 2 March 2016

Received in revised form 24 May 2016

Accepted 30 May 2016

Available online 01 June 2016

\section{Keywords:}

Antimicrobial peptide

Macrophages

Infectious diseases

Cathelicidin

Mycobacteria

\begin{abstract}
A B S T R A C T
Tuberculosis (TB), a disease caused by the human pathogen Mycobacterium tuberculosis, recently joined HIV/AIDS on the top rank of deadliest infectious diseases. Low patient compliance due to the expensive, long-lasting and multi-drug standard therapies often results in treatment failure and emergence of multi-drug resistant strains. In this scope, antimicrobial peptides (AMPs) arise as promising candidates for TB treatment.

Here we describe the ability of the exogenous AMP LLKKK18 to efficiently kill mycobacteria. The peptide's potential was boosted by loading into self-assembling Hyaluronic Acid (HA) nanogels. These provide increased stability, reduced cytotoxicity and degradability, while potentiating peptide targeting to main sites of infection. The nanogels were effectively internalized by macrophages and the peptide presence and co-localization with mycobacteria within host cells was confirmed. This resulted in a significant reduction of the mycobacterial load in macrophages infected in vitro with the opportunistic M. avium or the pathogenic M. tuberculosis, an effect accompanied by lowered pro-inflammatory cytokine levels (IL-6 and TNF- $\alpha$ ). Remarkably, intra-tracheal administration of peptide-loaded nanogels significantly reduced infection levels in mice infected with M. avium or $M$. tuberculosis, after just 5 or 10 every other day administrations. Considering the reported low probability of resistance acquisition, these findings suggest a great potential of LLKKK18-loaded nanogels for TB therapeutics.
\end{abstract}

c) 2016 Elsevier B.V. All rights reserved.

\section{Introduction}

Tuberculosis (TB) is a life-threatening disease caused by Mycobacterium tuberculosis. The World Health Organization recently reported about 9.6 million TB cases in 2014, having its death toll increased to around 1.5 million people, which places TB alongside HIV/AIDS as the deadliest infectious diseases [1].

The emergence of multidrug-resistant TB (MDR-TB) strains at an estimated rate of $3.3 \%$ is a further concern. MDR-TB may be mostly attributed to the selection of drug resistance mutations resulting from overuse and/or misuse of antibiotics. In addition, it has been demonstrated that primary transmission of MDR strains plays an important role in MDR-TB epidemics [2].

Tuberculosis transmission occurs mostly via the respiratory tract [3]. Mycobacteria are then phagocytized by alveolar macrophages and quickly spread across the lungs by lymphatic circulation. Weeks later,

\footnotetext{
* Corresponding authors.

E-mail addresses: jpsilva@deb.uminho.pt (J.P. Silva),fmgama@deb.uminho.pt (F.M. Gama).
}

bacilli may disseminate from the lungs to highly irrigated organs such as liver and kidneys $[4,5]$. Inside macrophages, mycobacteria are able to multiply within phagosomes, provided they arrest the phagosome maturation and its fusion with lysosomes, thereby avoiding contact with potent hydrolytic enzymes and antigen-presenting organelles present in the host macrophage [6,7].

TB control represents a major challenge. The only vaccine available, Bacille Calmette-Guérin (BCG), successfully prevents childhood TB but fails in protecting adults already infected or sensitized to mycobacteria [8]. Standard chemotherapy for drug-susceptible TB consists in the administration of a four antibiotic cocktail comprising isoniazid, rifampicin, pyrazinamide and ethambutol over a 6-month period. The presence of mycobacteria in stationary or low proliferating phases, as well as of multidrug-resistant strains, requires a more prolonged treatment regimen, involving the administration of pyrazinamide in combination with secondline drugs (e.g. fluoroquinolones, ethionamide, cycloserine, capreomycin or prothionamide) that can last up to 24 months $[9,10]$.

However, toxicity issues and elevated costs associated with these drugs, as well as low patient compliance to the long-lasting regimens, represent crucial drawbacks to the pharmacotherapy $[11,12]$. 
Additional major problems include: 1) the rapid degradation or excretion of most drugs (usually within hours); 2) the systemic distribution of drugs, in opposition to a more limited action upon their target cells and tissues; 3 ) the limited bioavailability and poor absorption via specific routes (e.g. oral) $[13,14]$. As such, finding new treatments to improve and shorten TB therapy, while comprising different action mechanisms (less prone to resistance acquisition) has become imperative [15,16].

In this scope, antimicrobial peptides (AMPs) have gained interest as promising candidates for the treatment of mycobacterial infections [17]. AMPs are typically cationic and amphipathic members of the innate immune system, present in many living organisms. They usually comprise a short amino acid chain (10-50 residues) and show a broader spectrum of antimicrobial activity compared to standard antibiotics, often attributed to their non-specific killing mechanism $[18,19]$. Moreover, this nonspecificity, along with the high metabolic costs associated with resistance-related mutations, is believed to have major implications in the reduced acquisition of AMP-resistance by mycobacteria [20,21].

The involvement of LL37, the only known human cathelicidin (a family of AMPs), in the killing of mycobacteria within macrophages has already been reported [22]. An ongoing clinical trial (NCT01580007) has evaluated the potential of the administration of 1,25-dihydroxyvitamin D3 (vitamin D) and phenylbutyrate, as synergistic inducers of LL37 expression, to enhance intracellular mycobacteria killing in M. tuberculosisinfected patients [23]. Several analogues of LL37 have also been engineered to enhance its activity. In the 18-mer LLKKK18, the polar uncharged residues glutamine and asparagine, and the negatively charged aspartic acid, are substituted by positively charged lysines. This results in a higher cationicity, hydrophobicity and ultimately higher antimicrobial activity, when compared to LL37 [24,25]. Indeed, we recently demonstrated LLKKK18 anti-mycobacterial activity against the opportunistic Mycobacterium avium (M. avium) growing in axenic conditions [26]. However, it remains unknown whether this peptide is able to reduce the mycobacterial load within infected macrophages or if it is active against more virulent mycobacteria.

The use of drug delivery systems may help circumvent some issues regarding the exogenous administration of AMPs, particularly by: 1) specifically targeting the peptide to a particular organ, allowing co-localization with bacteria; 2 ) preventing degradation by proteases; 3 ) improving stability and 4) increasing patient compliance through the possible reduction of the administration period [27,28].

Recently, we developed self-assembling Hyaluronic acid (HA) nanogels by grafting a hydrophobic molecule to HA [29]. The obtained amphiphilic conjugates self-assemble in aqueous environments and allow the entrapment of bioactive molecules in their hydrophobic core. In normal physiological conditions, macrophages do not internalize HA. However, Sladek and collaborators [30] showed that macrophages express the CD44 receptor in the beginning of an inflammatory response. Since activated macrophages express CD44 and can internalize HA [31], these nanogels seem to be a promising option to deliver drugs to infected macrophages.

In this work we evaluated the potential of LLKKK18 to efficiently kill the opportunistic M. avium and, most important, the human pathogen M. tuberculosis, using both in vitro and in vivo models of infection. We also hypothesized that the encapsulation of LLKKK18 into self-assembling HA nanogels could boost the potential of LLKKK18 to treat pulmonary mycobacterial infections, by enhancing the peptide's stability and targeting to infected macrophages, while reducing systemic toxicity and proteolytic degradability.

\section{Materials and methods}

\subsection{Materials}

Custom synthesis of LLKKK18 (KEFKRIVKRIKKFLRKLV) was obtained from Schafer-N (Copenhagen, Denmark). Sodium hyaluronate (7.46 kDa, $401 \mathrm{~g} / \mathrm{mol}$ per disaccharide unit) was purchased from
Lifecore Biomedical. AG 50W-X8 resin was acquired from Bio-Rad (USA).

All other reagents, including tetrabutylammonium fluoride hydrate (TBA-F), 11-amino-1-undecanethiol hydrochloride (AT), $\mathrm{N}$-hydroxysulfosuccinimide (NHS) and 1-ethyl-3-(3dimethylaminopropyl)carbodiimide hydrochloride (EDC) were purchased from Sigma Aldrich (Barcelona, Spain), unless stated otherwise.

\subsection{Production of self-assembling hyaluronic acid-based nanogels}

Production and characterization of self-assembling HA-based nanogels were performed according to a previously described method [29]. Firstly, a cationic exchange resin (AG $50 \mathrm{~W}$ ) was used to exchange the cations of sodium hyaluronate with the lipophilic tetrabutylammonium (TBA) ion, to enable HA solubilization in dimethyl sulfoxide (DMSO). For this, $1 \mathrm{~g}$ AG $50 \mathrm{~W}$ resin was mixed with $3.5 \mathrm{~g}$ TBA in ultrapure water, for $1 \mathrm{~h}$ at room temperature, under mild stirring. After washing and purification, the resin was moved to a $1 \%(\mathrm{w} / \mathrm{v}) \mathrm{HA}$ solution in ultra-pure water and the ion exchange of TBA ions with HA occurred for $2 \mathrm{~h}$ at room temperature, under mild stirring. The resin was then removed by centrifugation ( $2 \mathrm{~min}, 5000 \mathrm{rpm}$ ) in a Sigma 113 centrifuge and the resulting supernatant (HA-TBA) freeze-dried. Ion exchange was confirmed by ${ }^{1} \mathrm{NMR}$ spectroscopy. Crosslinking of the hydrophobic 11-amino-1-undecanethiol (AT) was performed through EDC/NHS chemistry [32]. The resulting solution was dialyzed (MWCO $1000 \mathrm{Da}$ ) against $150 \mathrm{mM} \mathrm{NaCl}$ for 3 days to remove any remaining TBA ions and 2 days in distilled water to further remove $\mathrm{NaCl}$. Finally, the solution was freeze-dried and the resulting material (HAAT) stored at room temperature until further use.

\subsection{Antimicrobial peptide encapsulation into HA-based nanogels}

Peptide encapsulation efficiency was quantified after mixing $100 \mu \mathrm{M}$ LLKKK18 (Schafer-N, Denmark) with $0.5 \mathrm{mg} / \mathrm{ml} \mathrm{HA} \mathrm{nanogels} \mathrm{in} \mathrm{Phos-}$ phate Buffered Saline (PBS) under mild rotation in a wheel, for $24 \mathrm{~h}$ at room temperature. Unloaded peptide was removed by transferring the solution into Amicon ${ }^{\circledR}$ Ultra-centrifugal filter units (Millipore) with a molecular weight cut-off of $100 \mathrm{kDa}$ and centrifugation for $2 \mathrm{~min}$ at $2000 \mathrm{rpm}$. The original volume in the concentrated solution containing the peptide-loaded nanogels was then restored. The amount of free and loaded LLKKK18 was quantified by the Waddell method [33] and the encapsulation efficiency was expressed as the percentage of loaded peptide. Waddell's is a sensitive and accurate method for determining protein concentration in a sample, based on the quantification of peptide linkages, thus not being affected by variations in protein composition and structure. Peptide concentration is calculated by subtracting the absorbance reading at $225 \mathrm{~nm}$ from the $215 \mathrm{~nm}$ reading and multiplying that difference by 0.144 .

The peptide-nanogel solution was sterilized through filtration using a $0.22 \mu \mathrm{m}$ polyethersulphone (PES) syringe filter.

For subsequent tests the amount of peptide mixed with the nanogels was set considering the observed encapsulation efficiency (around $70 \%$ ). Formulations were stored at $4{ }^{\circ} \mathrm{C}$ for up to 1 month until they were needed for further assays.

\subsection{Characterization of the nanogels}

Size distribution (diameter) and zeta potential of blank and peptideloaded nanogels were analyzed by Dynamic Light Scattering (DLS), as previously described [29]. Briefly, $1 \mathrm{ml}$ of the blank or peptide-loaded HA nanogels was dispersed in distilled water at $1 \mathrm{mg} / \mathrm{ml}$ and filtered with a $0.22 \mu \mathrm{m}$ polyethersulfone (PES) syringe filter. LLKKK18 was encapsulated at the concentration used for the subsequent tests $(100 \mu \mathrm{M})$. The samples were then analyzed in a polystyrene cell or in a folded capillary cell, for size distribution or zeta potential measurements, 
respectively, in a Zetasizer NANO ZS (Malvern Instruments Limited, UK) using a He-Ne gas laser (wavelength of $633 \mathrm{~nm}$ ) and a detector angle of $173^{\circ}$. For each sample, the polydispersity index (PdI), $z$-average diameter (corresponding to the mean hydrodynamic diameter) and zeta potential were evaluated after 6 repeated measurements. Zeta potential values were determined using Henry's equation.

\subsection{Bacterial strains}

The mycobacteria used in this study were selected based on their virulence. Two strains of the opportunistic Mycobacterium avium, 2447 and 25291, which form smooth transparent (SmT) colonies were obtained from the American Type Culture Collection (ATCC, Manassas, VA, USA). These strains were grown in Middlebrook 7H9 medium (Difco, Sparks, MD) supplemented with Middlebrook Albumin, Dextrose, Catalase (ADC) Supplement (Sigma-Aldrich, Barcelona, Spain) and $0.04 \%$ Tween 80 , at $37{ }^{\circ} \mathrm{C}$, according to the supplier's instructions. For CFU counting, these strains were plated in solid Middlebrook 7H10 medium supplemented with Middlebrook Oleic acid, Albumin, Dextrose, Catalase (OADC) Supplement (Sigma-Aldrich, Barcelona, Spain) and $0.5 \%$ glycerol. M. tuberculosis H37Rv was obtained from the Trudeau Institute Mycobacterial Collection and grown in conditions similar to M. avium (Middlebrook 7H9 medium supplemented with ADC and $0.04 \%$ Tween 80 , at $37^{\circ} \mathrm{C}$ ), according to the supplier's instructions. Colony forming units (CFUs) were grown in Middlebrook 7H11 medium supplemented with 10\% OADC (Sigma-Aldrich, Barcelona, Spain) and $0.5 \%$ glycerol, at $37^{\circ} \mathrm{C}$.

\subsection{Anti-mycobacterial activity in axenic culture}

Determination of the anti-mycobacterial activity of free and loaded peptide was performed as previously described [26]. Frozen aliquots of $M$. avium 2447 or $M$. tuberculosis H37Rv were thawed and diluted in 7H9 broth medium supplemented with 10\% ADC and 0.05\% Tween 80 to attain a final concentration of $2 \times 10^{4} \mathrm{CFU} / \mathrm{ml}$ and $50 \mu \mathrm{l}$ of this culture was added to a 96 -well plate, in triplicate. Serial dilutions of the peptide in distilled water, loaded or not into nanogels, were added to the mycobacteria to a final volume of $100 \mu \mathrm{l} /$ well. Distilled water was added to the control. The plate was then incubated in a humidified chamber at $37{ }^{\circ} \mathrm{C}$ during 4 or 7 days (for M. tuberculosis or M. avium, respectively) after which the antimicrobial effect was evaluated by plating serial dilutions of the suspensions on solid Middlebrook 7H10 (M. avium) or 7H11 (M. tuberculosis) agar medium supplemented with $10 \%$ OADC and $0.5 \%$ glycerol. CFUs in each plate were counted 1 or 3 weeks after plating, depending on the species. Mycobacterial survival after 4 (M. tuberculosis) or 7 days (M. avium) of incubation was expressed as a percentage relatively to a control group of mycobacteria grown without LLKKK18. The concentration needed to reduce $M$. tuberculosis growth by $50 \%\left(\mathrm{IC}_{50}\right.$ ) was calculated from a dose-effect plot.

\subsection{Culture of murine bone marrow-derived macrophages}

Bone marrow-derived cells (BMM $\Phi$ ) from $\mathrm{C} 57 \mathrm{BL} / 6$ mice were isolated from femurs and tibia, removed under aseptic conditions, according to a previously reported method [34]. Bones were flushed with $5 \mathrm{ml}$ of Dulbecco's Modified Eagle's Medium (DMEM) supplemented with $10 \%$ Fetal Bovine Serum (FBS), passed through a cell strainer and centrifuged at $1200 \mathrm{rpm}, 6 \mathrm{~min}$, at $4{ }^{\circ} \mathrm{C}$. The pellet was resuspended in $10 \mathrm{ml}$ DMEM supplemented with 20\% L929-cell conditioned medium (LCCM) and cells were allowed to differentiate into macrophages for 7 days in $100 \mathrm{~mm}$ diameter Petri dishes. Another $10 \mathrm{ml}$ of DMEM containing $20 \%$ LCCM was added to the cells at day 4 . At day 7, differentiated cells were scraped from the Petri dishes and seeded at the desired concentration in 24 or 96 well plates.

\subsection{Viability and metabolic activity assays}

\subsubsection{MTS reduction test}

The cells' metabolic activity in the presence of the LLKKK18-loaded NPs was assessed by measuring the reduction of the tetrazolium salt MTS (3-(4,5-dimethyl-2-yl)-5-(3-carboxy-methoxyphenyl)-2-(4sulfophenyl)-2H tetrazolium). BMMФ were seeded in 96-well plates at $5 \times 10^{4}$ cells/well and allowed to adhere overnight. The cell culture medium was then replaced by empty HA nanogels at different concentrations, prepared in DMEM to a final volume of $200 \mu \mathrm{l}$. After $24 \mathrm{~h}$, at $37^{\circ}$ C, $5 \% \mathrm{CO}_{2}, 20 \mu \mathrm{l}$ of MTS (CellTiter 96® Aqueous One Solution Cell Proliferation Assay, Promega, WI, USA) was added per well and the plate was further incubated for $2 \mathrm{~h}$ at $37^{\circ} \mathrm{C}$, protected from light, to allow the formazan reduction to occur. Metabolic activity was then measured spectrophotometrically at $490 \mathrm{~nm}$ in a Bio-Rad Model 680 (Bio-Rad laboratories, UK) microplate reader.

\subsubsection{Trypan blue dye exclusion assay}

BMMФ were seeded in 96-well plates at the concentration of $5 \times 10^{4}$ cells/well. The cells were incubated for $24 \mathrm{~h}$ in the presence of the blank and peptide-loaded NPs, in a final volume of $100 \mu \mathrm{l} /$ well. On the following day, the plate was placed on ice for $1 \mathrm{~h}$ to detach $B M M \Phi$, which were then scraped and mixed with Trypan blue (1:1) for cell counting using a Neubauer Chamber. Trypan blue is only uptaked by cells with a disrupted cell membrane (non-viable), thus allowing the distinction between viable and non-viable cells.

\subsubsection{Live/Dead assay}

Cell viability was also assessed using the Live/Dead ${ }^{\circledR}$ Viability/Cytotoxicity Kit (Invitrogen, CA, USA), according to the manufacturer's instructions. ВMМФ were seeded in 96-well plates at $5 \times 10^{4}$ cells/well and allowed to adhere overnight. The cell culture medium was then replaced by fresh culture medium, non-loaded (blank) or peptide-loaded nanogels at the desired concentrations, and cells were incubated for $24 \mathrm{~h}$ at $37{ }^{\circ} \mathrm{C}, 5 \% \mathrm{CO}_{2}$. Cell culture medium was then replaced by $100 \mu \mathrm{l}$ of PBS containing $1 \mu \mathrm{M}$ calcein AM and $2 \mu \mathrm{M}$ ethidium homodimer-1 (EthD-1) and incubated for $30 \mathrm{~min}$ at $37^{\circ} \mathrm{C}, 5 \% \mathrm{CO}_{2}$. Calcein$\mathrm{AM}$ and $\mathrm{EthD}-1$ are indicators of intracellular esterase activity and plasma membrane integrity, respectively. Cells were observed under a fluorescence microscope (Leica DMIRE2, with a DCF350FX camera) and pictures taken from five random fields for each condition. The amount of viable cells was expressed as a percentage relatively to a control with no nanogels or peptide.

\subsubsection{Apoptotic cell death detection}

Evaluation of apoptotic cell death was performed using an in situ cell death detection kit (Roche, UK), based on the Terminal deoxynucleotidyl transferase dUTP nick end-labeling (TUNEL) assay. ВMМФ were seeded on top of coverslips, in a 24-well plate, at $5 \times 10^{5}$ cells/well. Infection with M. avium was performed at a multiplicity of infection (M.O.I.) $=2$ and both infected and non-infected cells were treated as described in the sections above. After $24 \mathrm{~h}$, the cells were fixed using $2 \%$ paraformaldehyde (PFA) and TUNEL was applied according to the manufacturer's instructions. The coverslips were observed under a fluorescence microscope (Leica DMIRE2, with a DCF350FX camera) and at least 300 cells were counted per condition.

\subsubsection{Free nitric oxide estimation}

The accumulation of extracellular nitrites $\left(\mathrm{NO}_{2}\right)$, an indicator of nitric oxide synthase activity, was quantified by the Griess reaction, according to a previously described protocol [35]. Nitrites react with Griess reagent ( $1 \%$ sulfanilamide- $0.1 \%$ naphthylethylenediamine dihydrochloride in $5 \%$ concentrated $\mathrm{H}_{3} \mathrm{PO}_{4}$ ), forming a pink azo product [36]. ВММФ were seeded in 24-well plates at the concentration of $5 \times 10^{5}$ cells/well and further incubated for $24 \mathrm{~h}$ with blank and loaded nanogels. $\mathrm{NO}_{2}$ accumulation was measured by mixing $50 \mu \mathrm{l}$ of cell 
culture medium from each well with an equal volume of Griess reagent, followed by an incubation period of $10 \mathrm{~min}$ at room temperature, protected from light. Absorbance was measured at $550 \mathrm{~nm}$ in a microplate reader and the nitrite concentration determined from a calibration curve using sodium nitrite as a standard.

\subsection{Intracellular effect of the nanogels on mycobacteria killing}

The intracellular reduction of the mycobacterial burden was assessed in ВММФ infected with either M. avium 2447 or M. tuberculosis H37Rv, as previously described [26]. ВММФ were seeded at $5 \times 10^{5}$ cells/ $\mathrm{ml}$ in 24-well plates, allowed to adhere overnight and infected with either mycobacteria strain at a multiplicity of infection of 2 for $4 \mathrm{~h}$ to allow mycobacteria internalization. After that period, noninternalized mycobacteria were removed by 4 washes in pre-warmed DMEM and cells incubated with the blank or LLKKK18-loaded NPs. A PBS solution was used as a control. After a 7- or 4-day incubation period, for $M$. avium and M. tuberculosis, respectively, ВММФ were permeabilized with saponin and mycobacteria survival was evaluated by plating serial dilutions on 7H11 agar plates. CFUs were then counted after 2 weeks of incubation at $37{ }^{\circ} \mathrm{C}, 5 \% \mathrm{CO}_{2}$. The initial intracellular bacterial burden was assessed identically at day 0 . Of note, an independent researcher additionally performed a blind experiment of the M. avium assay.

\subsection{Internalization studies}

\subsubsection{Confocal microscopy}

M. avium strain 104 expressing recombinant GFP [37] was used to visualize intracellular mycobacteria, similarly to a previously described method [38]. ВMMФ were seeded at $5 \times 10^{5}$ cells/well in 24 -well plates with $12 \mathrm{~mm}$ diameter coverslips. Mycobacteria were added at a multiplicity of infection of 10 and, after $4 \mathrm{~h}$, each well was extensively washed 4 times with pre-warmed DMEM. The macrophages were then incubated for different time points with LLKKK18 and HA nanogels fluorescently labeled with TAMRA (Schafer-N, Denmark) or Alexa Fluor 488, respectively. Free LLKKK18 was added at a concentration below the toxicity threshold $(10 \mu \mathrm{M})$, whereas encapsulated LLKKK18 was added at $30 \mu \mathrm{M}$ per well in $0.5 \mathrm{mg} / \mathrm{ml}$ HA nanogels. At the defined endpoints, cells were fixed with $2 \%$ paraformaldehyde (in PBS) for 20 min and the coverslip placed on top of a microscopy slide for observation under a Confocal Scanning Laser Microscope (CLSM, Olympus BX61, Model FluoView 1000), comprising a Laser DM 405/488/515/559/635 and the following emission filters: BA 505-540 (green channel), BA 575-620 (orange channel) and BA 655-755 (red channel). Images were analyzed on the software FV10-ASW 4.2.

\subsubsection{MALDI-ToF mass spectrometry}

Internalization and intracellular degradation of LLKKK18 were also assessed by Matrix-assisted laser desorption/ionization-time of flight (MALDI-ToF) mass spectrometry, according to a previously reported protocol [39]. This method allows the measurement of the total amount of intact internalized peptide and the identification of possible degraded products. Briefly, BMM $\Phi$ seeded at $5 \times 10^{5}$ cells/well in 12 -well plates were incubated $\left(37^{\circ} \mathrm{C}, 5 \% \mathrm{CO}_{2}\right.$ ) for different time points in the presence of $5 \mu \mathrm{M}$ (corresponding to $5 \mathrm{pmol} / \mu \mathrm{l}$ ) of free or loaded peptide, containing an isotope tag of four non-deuterated glycines ( $\left[{ }^{1} \mathrm{H}\right]$ LLKKK18, Schafer-N, Denmark). Peptides were also biotinylated to facilitate extraction, purification, concentration and desalting, which was performed with streptavidin-coated magnetic beads.

After the incubation period, cells were scraped and centrifuged for $2 \mathrm{~min}$ at $640 \mathrm{~g}$ in an Eppendorf ${ }^{\circ}$ 5430R centrifuge (Eppendorf, NY, USA) to recover intact cells. The pellet was further washed with $1 \mathrm{ml}$ Buffer A (50 mM Tris- $\mathrm{HCl}$, (pH 7.4), $0.1 \mathrm{mg} / \mathrm{ml}$ Bovine Serum Albumin (BSA)) and again centrifuged for $2 \mathrm{~min}$ at $640 \mathrm{~g}$. $1 \mathrm{pmol}$ of peptide with four bi-deuterated glycines $\left(\left[{ }^{2} \mathrm{H}\right]\right.$ LLKKK18) was then added to the pellet and the cells were lysed for $15 \mathrm{~min}$ at $100{ }^{\circ} \mathrm{C}$ in the presence of $150 \mu$ lysis solution ( $0.3 \%$ Triton $\mathrm{X}-100,1 \mathrm{M} \mathrm{NaCl})$. The lysate was centrifuged for $5 \mathrm{~min}$ at $12,000 \mathrm{~g}$ and $4{ }^{\circ} \mathrm{C}$, and the supernatant transferred to a clean tube. The pellet was further washed with $850 \mu$ of Buffer A, again centrifuged for $5 \mathrm{~min}$ at $12,000 \mathrm{~g}$ and $4{ }^{\circ} \mathrm{C}$, and the supernatant was combined with the previous one. A $10 \mu \mathrm{l}$ solution of washed streptavidin-coated magnetic beads (Dynabeads MyOne Streptavidin C1, Invitrogen, UK) was added to the lysate and stirred gently for $1 \mathrm{~h}$ at room temperature, to allow the binding of the beads to the biotinylated peptides. The beads were then immobilized with a Dynabeads ${ }^{\circledR}$ MPC $®-S$ magnetic particle concentrator (Invitrogen, UK), the supernatant was removed and the beads washed twice with $200 \mu \mathrm{l}$ of Buffer A, twice with $200 \mu \mathrm{l}$ of Buffer B (50 mM Tris- $\mathrm{HCl}$, (pH 7.4), $0.1 \mathrm{mg} / \mathrm{ml} \mathrm{BSA}, 0.1 \% \mathrm{SDS}$ ), twice with $200 \mu \mathrm{l}$ of Buffer C (50 mM Tris- $\mathrm{HCl},(\mathrm{pH} 7.4), 0.1 \mathrm{mg} / \mathrm{ml} \mathrm{BSA}, 1 \mathrm{M} \mathrm{NaCl}$ ) and twice with $200 \mu$ of distilled water. Saturation of the beads ensued, by incubating them for 2 min with $400 \mathrm{pmol}$ of biotin. The beads were then washed with $50 \mu \mathrm{l}$ of a 1:1 acetonitrile/water solution, and after removing that solution, mixed with $5 \mu \mathrm{l}$ of matrix ( $\alpha$-cyano-4-hydroxycinnamic acid (CHCA) saturated solution in acetronitrile:0.1\% TFA (1:1)). After mixing the beads with CHCA matrix, $1 \mu \mathrm{l}$ of each sample was spotted on the MALDI sample holder. Mass spectra were acquired in a 4800 Plus MALDI TOF/TOF Analyzer (Sciex, MA, USA) reflector positive mode for the ranges $m / z=2750-2850$ and $m / z=1000-3000$. The obtained mass spectra were internally calibrated for $\left[{ }^{1} \mathrm{H}\right]$ LLKKK18 at $\mathrm{m} / z=$ 2783.5 and $\left[{ }^{2} \mathrm{H}\right]$ LLKKK18 at $m / z=2791.5$.

The area of the peaks of the $[\mathrm{M}+\mathrm{H}]^{+}$signals (including all isotopes) of intact $\left[{ }^{1} \mathrm{H}\right]$ LLKKK18 and $\left[{ }^{2} \mathrm{H}\right]$ LLKKK18 was determined and the amount of intact $\left[{ }^{1} \mathrm{H}\right]$ LLKKK18 was calculated from the area ratio.

\subsection{Cytokines expression}

Levels of Interleukin-6 (IL-6) and Tumor Necrosis Factor- $\alpha$ (TNF- $\alpha$ ) were determined by ELISpot (eBiosciences, Carlsbad, CA, USA) [40] in infected and non-infected macrophages after incubation with the formulations. Briefly, ВMMФ seeded in 96 -well plates at $5 \times 10^{4}$ cells/ well and allowed to adhere overnight. A part of the macrophages was then infected with $M$. tuberculosis at a M.O.I. = 2 and both infected and non-infected cells were incubated with either blank or peptideloaded nanogels. Peptide was loaded at a concentration of $100 \mu \mathrm{M}$. PBS was added to the control group. At defined time points, cell culture medium was collected from each well and $50 \mu \mathrm{l}$ of each condition placed on 96-well plates previously coated with IL-6 or TNF- $\alpha$ antibodies (eBiosciences, Carlsbad, CA, USA). Prior to the addition of the samples, the antibody-coated plate was washed and blocked for $1 \mathrm{~h}$ at room temperature with $200 \mu$ Assay Diluent. The antibodies were then allowed to bind the samples' proteins for $2 \mathrm{~h}$ at room temperature. The wells were washed four times with PBS containing $0.05 \%$ Tween 80 and further incubated with the secondary antibodies (1:100 dilution) for $1 \mathrm{~h}$ at room temperature. Fifty $\mu \mathrm{l}$ of horseradish peroxidase-labeled avidin was then added to the wells and the plate was incubated for $30 \mathrm{~min}$ at room temperature, protected from light. After thorough washing of the wells, color development was achieved by adding $50 \mu \mathrm{l}$ of 3,3',5,5'Tetramethylbenzidine (TMB) to the wells and incubating the plate for 20 min, protected from light, after which the reaction was stopped by addition of $25 \mu \mathrm{l}$ of stop solution. Absorbance was measured at $450 \mathrm{~nm}$ in a Bio-Rad Model 680 (Bio-Rad laboratories, UK) microplate reader and total protein expression levels determined from calibration curves using standard concentrations of each protein.

\subsection{In vivo assays}

Female C57BL/6 mice aged 6-8 weeks were purchased from Charles River Laboratories, Inc. (Barcelona, Spain) and housed at the ICVS animal facility under a $12 \mathrm{~h}$ dark/light cycle in a room with controlled temperature and humidity. Standard chow and water were supplied ad 
libitum. All animal experiments were performed according to the European Union Directive 86/609/EEC and were approved by the Portuguese Veterinary authorities (Direção Geral de Veterinária).

Mice were infected aerogenically through exposure to an aerosolized suspension of each mycobacteria strain mentioned in Section 2.5 for $40 \mathrm{~min}$ using a Glas-Col Inhalation Exposure System: a $2 \times 10^{6} \mathrm{CFU} / \mathrm{ml}$ suspension resulted in the implantation of $\sim 20 \mathrm{CFU}$ of mycobacteria in the lungs of each mouse [41]. After 3 months to allow the infection to reach a chronic stage, mice were anesthetized with an intraperitoneal injection of ketamine (Imalgene ${ }^{\circledR}$ ) and medetomidine (Dorbene ${ }^{\circledR}$ ).

HA nanogels were prepared at a concentration of $0.5 \mathrm{mg} / \mathrm{ml}$ and administered either empty or loaded with $100 \mu \mathrm{M}$ LLKKK18. PBS solution was used as a control. Either 5 or 10 doses of the treatments ( $50 \mu \mathrm{l}$ each) were administered intra-tracheally every other day, using a MicroSprayer ${ }^{\circledR}$ aerosolizer (IA-1C; Penn-Century, Philadelphia, PA, USA) attached to a high-pressure syringe (FMJ-250; PennCentury) [42]. The aerosol is generated through a sub-miniaturized atomizer situated in the tip of a stainless steel tube, which is attached to a hand-operated, high-pressure syringe. For administration, mice were placed with their dorsa against an acrylic platform lifted at an angle of about $45^{\circ}$. Mice were suspended with a rubber band by their upper teeth and another rubber band was used to prevent lateral movements during endotracheal administration. A lamp was also used to provide proper illumination of the trachea. Blunted forceps were used to help displace the tongue to allow proper oropharyngeal exposure.

Mice were sacrificed by $\mathrm{CO}_{2}$ asphyxiation one week after the last treatment and lungs were aseptically removed. The right superior lobe was collected in $2 \%$ paraformaldehyde for histological analysis and the remainder was homogenized in DMEM. A pre-treatment with collagenase $\left(37^{\circ} \mathrm{C}, 30 \mathrm{~min}\right.$ ) was applied to degrade the extracellular matrix and saponin was finally added to the lung homogenate to release intracellular mycobacteria. Serial dilutions were plated on Middlebrook 7H11 agar and CFUs were counted after about 1 or 3 weeks of incubation at $37^{\circ} \mathrm{C}$, depending on the species.

\subsection{Statistical analysis}

Statistical analysis was performed using GraphPad Prism 5 (GraphPad Software, La Jolla, CA). Normality of the distributions was examined prior to each analysis using Kolmogorov-Smirnov and ShapiroWilk normality tests, and taking into account the acceptability of skewness and kurtosis values. According to the results from the normality tests, one-way ANOVA, followed by a Newman-Keuls comparison post-test was conducted wherever appropriate. A 95\% confidence interval was considered as statistical significant.

\section{Results}

\subsection{Characterization of the nanogels}

In this work we used hydrophobized HA nanogels capable of self-assembling in aqueous environments, which had been previously developed at our lab [29]. These nanogels allowed an encapsulation efficiency of LLKKK18 of about 70\%. We showed that at a concentration of $0.5 \mathrm{mg} / \mathrm{ml}$, the thyolated HA forms nanogels with a diameter of $133 \pm 4 \mathrm{~nm}$ (Fig. 1A), with a polydispersity index (PDI) of $0.27 \pm$ 0.02 . An average zeta potential of $-23.5 \pm 0.5 \mathrm{mV}$ was obtained (Fig. $1 \mathrm{~B})$, a value similar to the one presented by Pedrosa and co-workers [29]. However, both size and zeta potential were significantly altered after loading of the nanogels with the positively charged LLKKK18 (Fig. 1A-B). Indeed, in the presence of the peptide, the average diameter increases to $533 \pm 13 \mathrm{~nm}$, with a PDI of $0.1 \pm 0.1$. This small PDI indicates that peptide loading resulted, remarkably, in a monomodal size distribution, compared to the bimodal distribution of the empty nanogels. The presence of the peptide also resulted in a change in zeta potential to $2.4 \pm 0.1 \mathrm{mV}$, which may be attributed to the high cationicity of the peptide $(+8)$ and neutralization of the hyaluronic acid negative charge [43].

Evaluation of the empty (non-loaded) nanogels effect on the macrophages metabolic activity was assessed using the MTS reduction test. As observed in Fig. 1C, HA nanogels induce a dose-dependent decrease in metabolic activity, showing a significant reduction at $1.5 \mathrm{mg} / \mathrm{ml}$. As such, a concentration of $0.5 \mathrm{mg} / \mathrm{ml} \mathrm{HA}$ nanogels was selected for subsequent assays.

\subsection{Toxicity of LLKKK18-loaded nanogels towards BMMФ}

Two different methods were used to evaluate cell death caused by the loaded nanogels: Live/Dead (Fig. 2A) and Trypan Blue Exclusion assays (Fig. 2B). Results from both assays revealed that loaded LLKKK18 did not cause BMMФ death up to a $100 \mu \mathrm{M}$ concentration, after $24 \mathrm{~h}$ (Fig. 2A-B). These results are even more relevant considering that at $5 \mu \mathrm{M}$ the free peptide reduced cell viability in about $21-26 \%$ and at $100 \mu \mathrm{M}$ more than $90 \%$ of the cells were non-viable.

Nevertheless, at $200 \mu \mathrm{M}$, loaded LLKKK18 induces a significant decrease in cell viability, causing approximately $44 \%$ and $34 \%$ of cell death, after the Live/Dead and Trypan blue assays, respectively.

Additionally, we observed no significant effect in terms of the number of apoptotic cells, regardless of the treatment or whether the ВММФ were or not infected with M. avium 2447 (Fig. 2C). We also quantified the concentration of nitrites released to the cell culture medium by (RNS) levels, in particular nitric oxide. These are commonly produced by macrophages as a way of coping with foreign particles or microorganisms and may be deleterious to the cells themselves [44]. Although the HA nanogels did not induce the overproduction of $\mathrm{NO}_{2}$, a significant increase in extracellular nitrites was found in the presence of the peptide (Fig. 2D). Nevertheless, the nitrite concentration remained very low (less than $5 \mu \mathrm{M}$ ) as compared to other reports of nitrite production by macrophages [45].

\subsection{Mycobactericidal effect of LLKKK18}

Previously, we reported that a LLKKK18 concentration of $58.81 \pm$ $0.07 \mu \mathrm{M}$ reduced the axenic growth of M. avium to 50\% [26]. Compared with the MICs of standard antibiotics against M. avium, this value (corresponding to about $135 \mu \mathrm{g} / \mathrm{ml}$ ) may be considered high. Indeed, Heifets and co-workers [46] reported MICs ranging between 0.6 and above $10 \mu \mathrm{g} / \mathrm{ml}$ for isoniazid, $0.12-16.0 \mu \mathrm{g} / \mathrm{ml}$ for rifampicin and $0.94-15 \mu \mathrm{g} / \mathrm{ml}$ for ethambutol. Recently, Andrejak et al. [47] reported MICs of 8-> $16 \mu \mathrm{g} / \mathrm{ml}$ for rifampicin, $2->4 \mu \mathrm{g} / \mathrm{ml}$ for clarithromycin and $16-32 \mu \mathrm{g} / \mathrm{ml}$ for ethambutol. These authors also determined the MIC of combined antibiotics, observing that, for example, the MIC of rifampicin lowered from $16 \mu \mathrm{g} / \mathrm{ml}$ (alone) to $4 \mu \mathrm{g} / \mathrm{ml}$ when combined with ethambutol.

To evaluate if LLKKK18's effect remained after encapsulation in the HA nanogels, axenic cultures of M. avium were incubated with different concentrations of peptide loaded in $0.5 \mathrm{mg} / \mathrm{ml} \mathrm{HA}$. It is worth noticing that as the peptide is loaded into the HA nanogels, its readily available concentration will not be as high as it would be expected from its free (non-loaded) form. In this sense, it is reasonable to believe that a higher concentration would be required to achieve similar results, hence the increase in the concentration of loaded peptide. As observed in Fig. 3A, the encapsulated AMP requires a higher dose $(200 \mu \mathrm{M})$ to induce a significant reduction of $M$. avium growth.

The effect of LLKKK18 on mycobacteria residing within macrophages was further evaluated after incubating $M$. avium-infected ВММФ for 7 days in the presence of the peptide-loaded nanogels.

Fig. 3B indicates that peptide-loaded nanogels resulted in the significant reduction of mycobacterial load within ВММФ, being this effect stronger for higher peptide concentrations. Indeed, approximately 1.9 
A

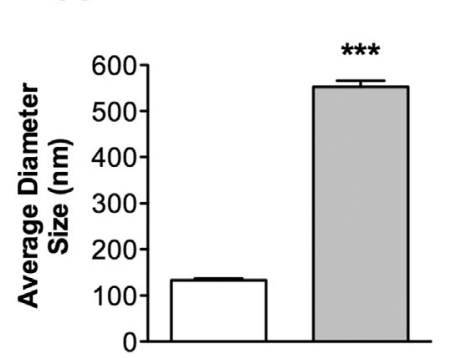

C
B

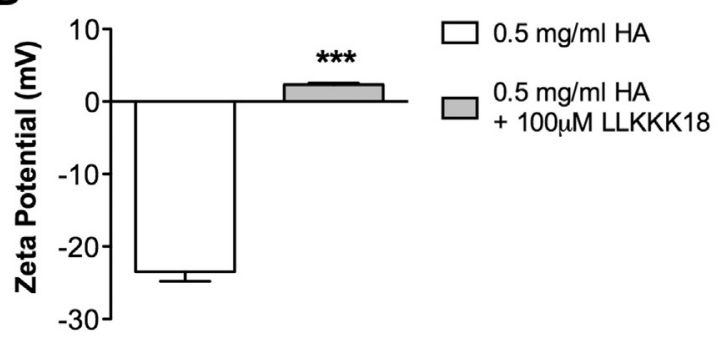

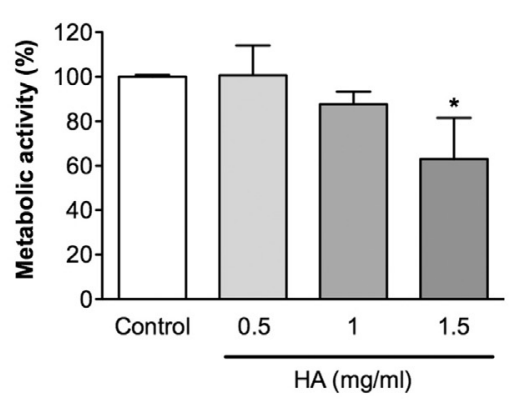

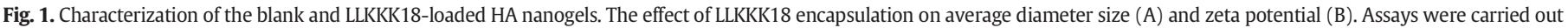

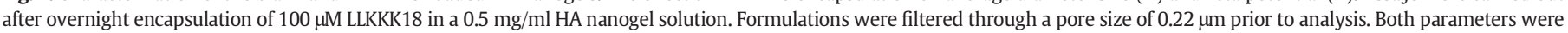

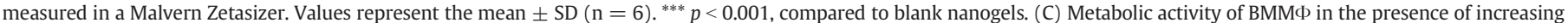

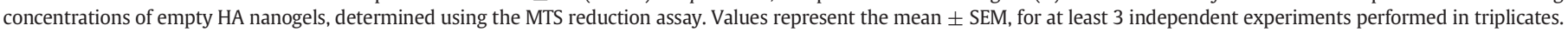
* $p<0.05$, compared to control (cells alone).

log-, 2.2 log- and 4.4 log-reductions were attained for 50, 100 and $200 \mu \mathrm{M}$, respectively. Neither the free peptide nor empty nanogels had any antimycobacterial effect on infected macrophages. Interestingly, when added separately, LLKKK18 and nanogels yielded no mycobacteria killing (Fig. 3C), leading to the conclusion that the nanogel supports the targeted intracellular delivery of the peptide.
A

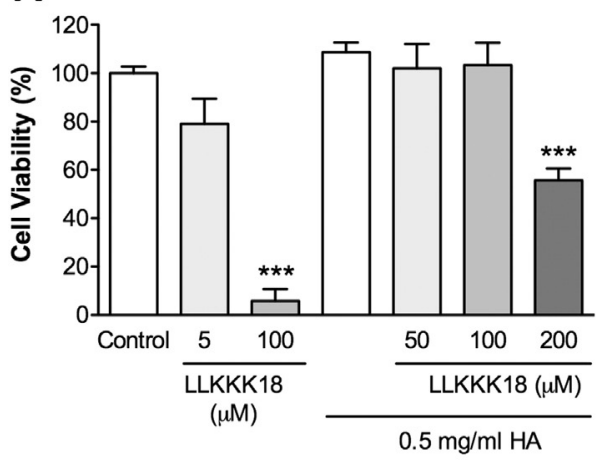

C

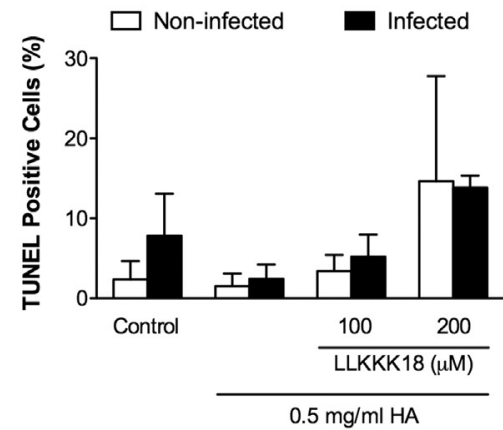

B

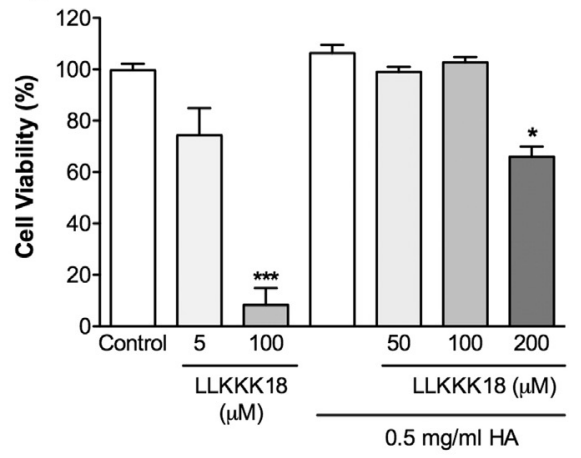

D

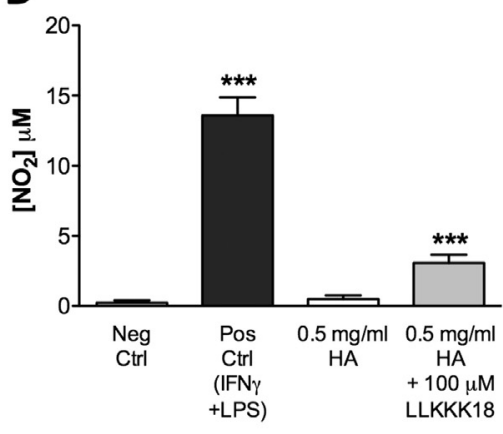

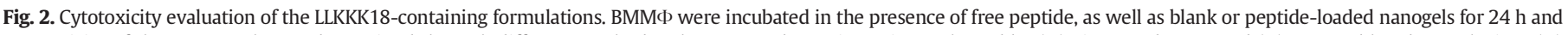

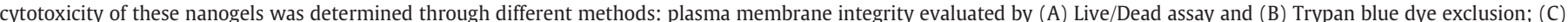

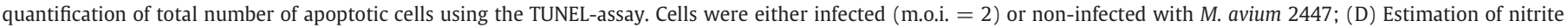

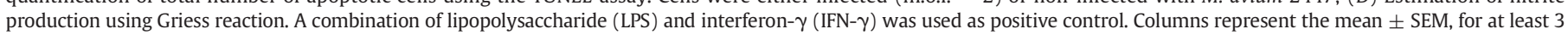
independent experiments performed in triplicates. ${ }^{*} p<0.05 .{ }^{* * *} p<0.001$, compared to respective controls. No statistically significant differences were observed in the TUNEL assay. 
A
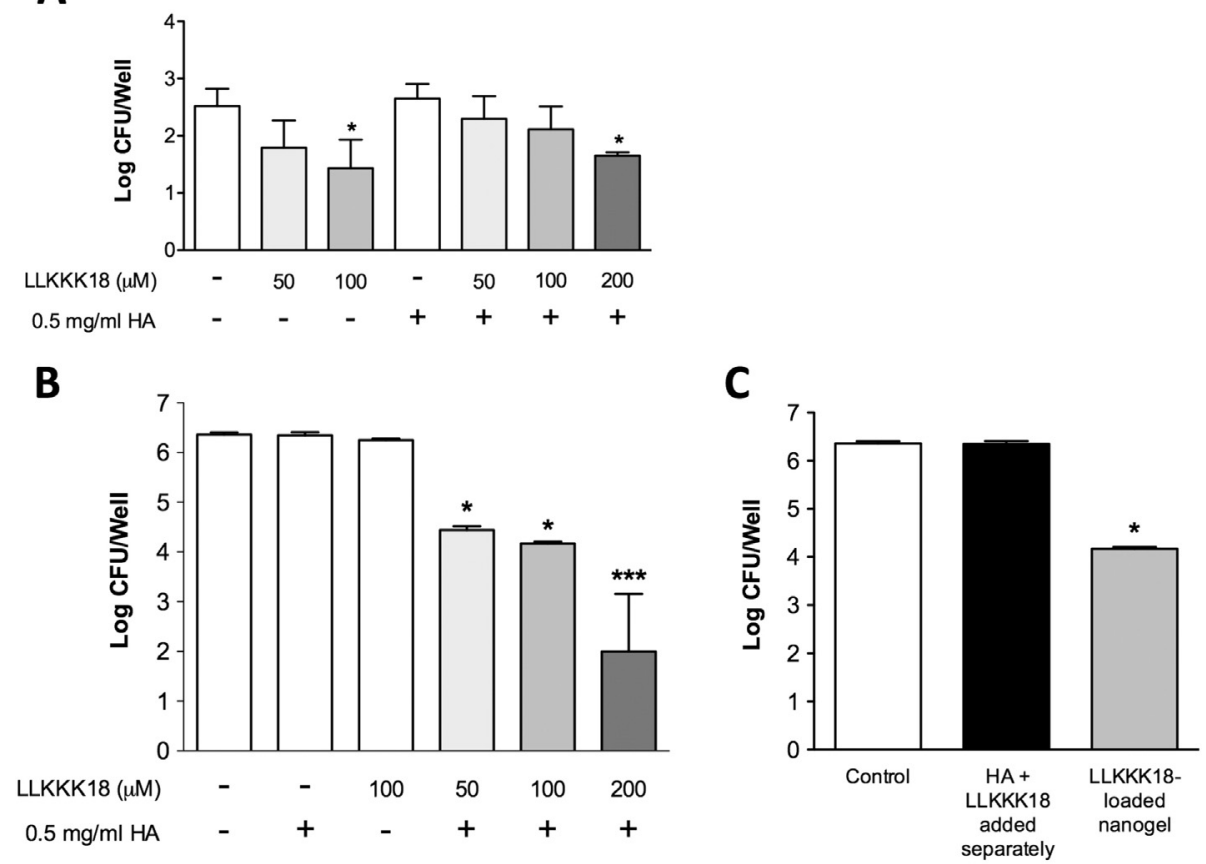

D

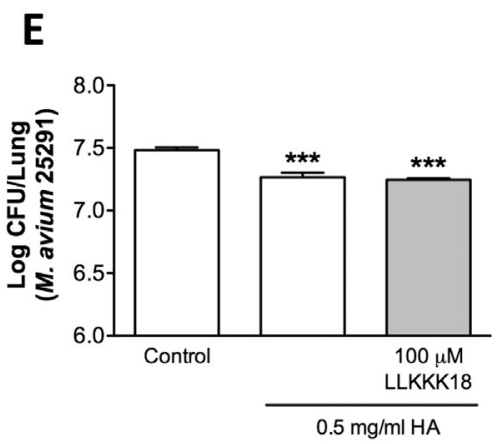

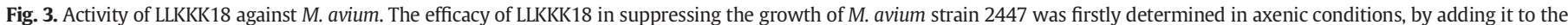

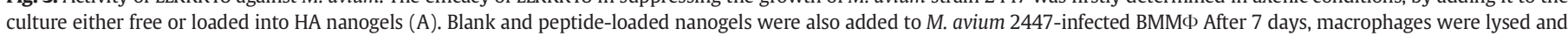

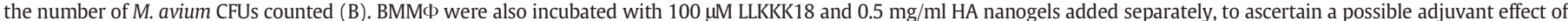

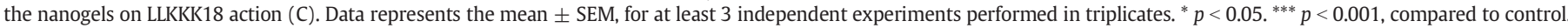

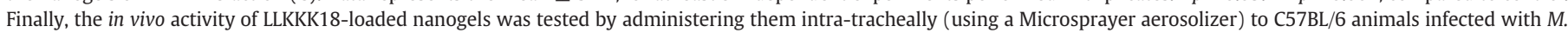

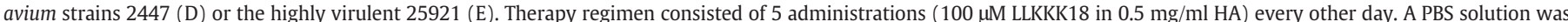
administered to the control group. Data represents the mean $\pm S D$, for at least 9 mice per group. ${ }^{* * *} p<0.001$, compared to control.

The in vivo efficacy of the LLKKK18-loaded nanogels against opportunistic M. avium strains 2447 and 25291 (highly virulent) was evaluated by treating infected mice after a 3-month infection settlement period. Loaded nanogels were administered intra-tracheally 5 times every other day and lungs were removed for CFU counting one week after the last treatment.

Fig. 3D shows a significant reduction $(\sim 1 \log )$ of the M. avium 2447 load in the lungs of infected mice, a relevant decrease considering the low concentration $(100 \mu \mathrm{M}$, which corresponds to about $8 \mathrm{mg} / \mathrm{kg}$ ) and short therapy regimen applied. It should be noted that Bermudez et al. [48] reported a significant reduction of $M$. avium in the lungs of infected mice after the daily administration of $100 \mathrm{mg} / \mathrm{kg}$ clarithromycin (a concentration 12.5 times higher than the one herein reported), during a 4week therapy. Similarly, Roque et al. [49] attained about 1-log reduction in liver and spleen of infected mice after 4 weeks of therapy consisting on the daily administration of three combined drugs at high concentrations (4.67 mg/ml rifampicin, $22.5 \mathrm{mg} / \mathrm{ml}$ clarithromycin, and $2.92 \mathrm{mg} / \mathrm{ml}$ ).

Since mycobacteria growth in untreated mice was not very high, we also tested the effect of the peptide on the highly virulent $M$. avium strain 25291. We expected that a larger mycobacterial growth would allow the detection of a more pronounced effect of the peptide.
However, as shown in Fig. 3E, both loaded and empty nanogels significantly reduced M. avium 25291 growth by about $0.3 \mathrm{log}$.

\subsection{Internalization and intracellular distribution of LLKKK18}

ВММФ were infected with an M. avium strain expressing recombinant GFP [37] and further incubated with LLKKK18 tagged with a fluorescent red label (TAMRA) loaded into HA nanogels. Fig. 4A shows that the loaded peptide uptake increases over time (up to $7 \mathrm{~h}$ ), as indicated by an increasing larger red area (peptide) in the cytoplasm. Most important, it is possible to identify several situations in which the peptide seems to co-localize with mycobacteria, as noted by the overlapping of the fluorescent labels (Fig. 4B). This suggests a possible direct antimycobacterial effect of the peptide inside macrophages. Both peptide and mycobacteria were detected throughout the cytosol, implying that such co-localization may be non-specific. Using the $3.5 \mathrm{~h}$ time point as an example, it was also possible to observe the uptake of free peptide (Fig. 4C). However, as previously noted, the free peptide is not able to reduce the infection burden in the macrophages, again highlighting the role of the nanogel as a targeting carrier. 
A

A

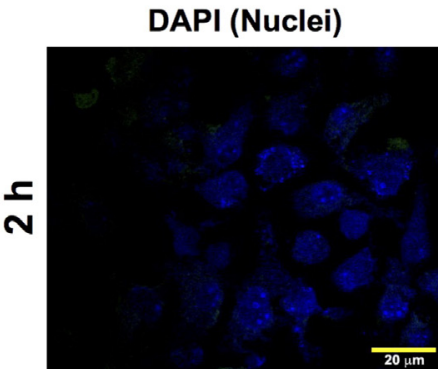

TAMRA (LLKKK18)-HA
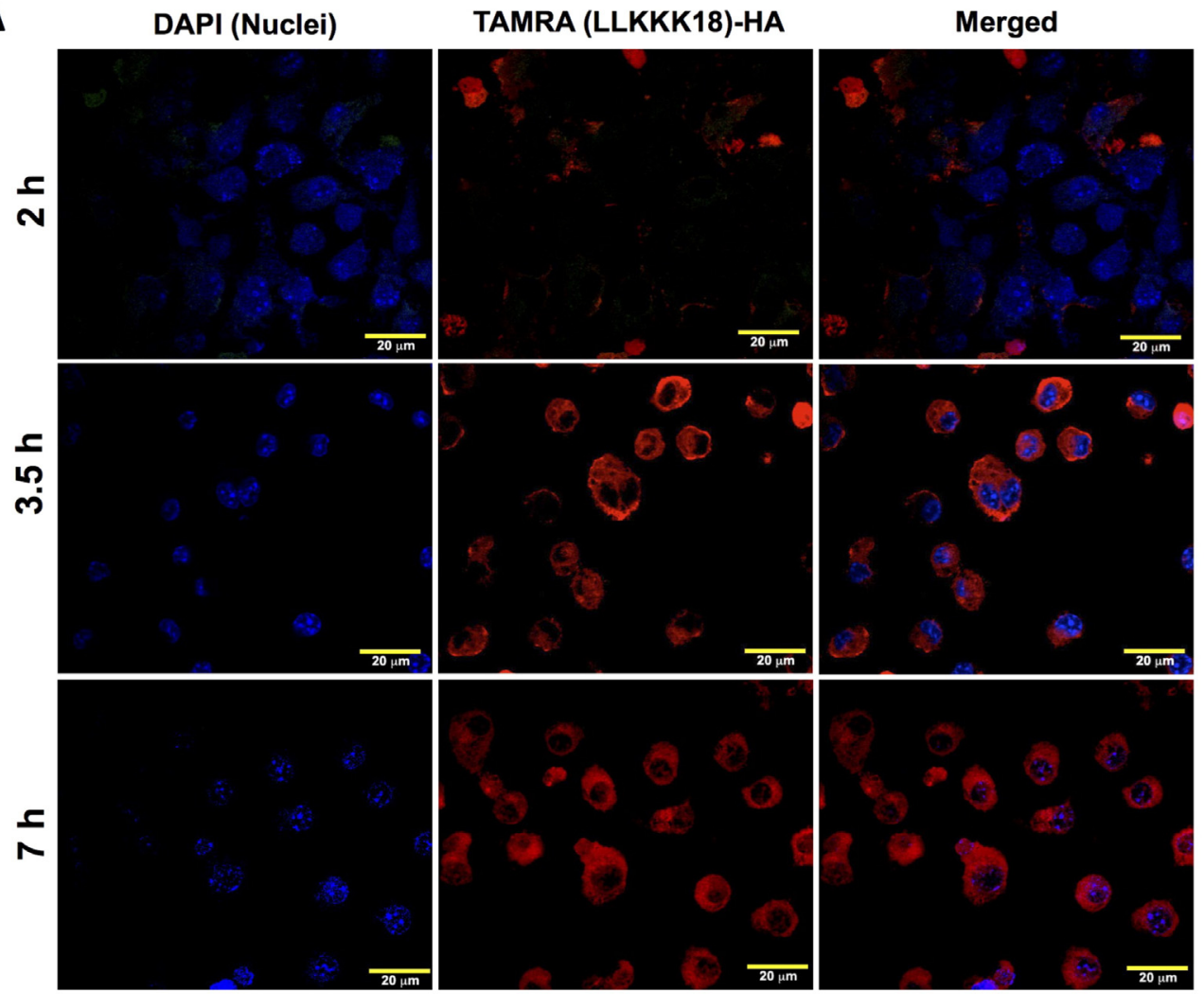

B

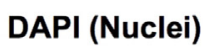

TAMRA (LLKKK18)-HA GFP (M. avium)
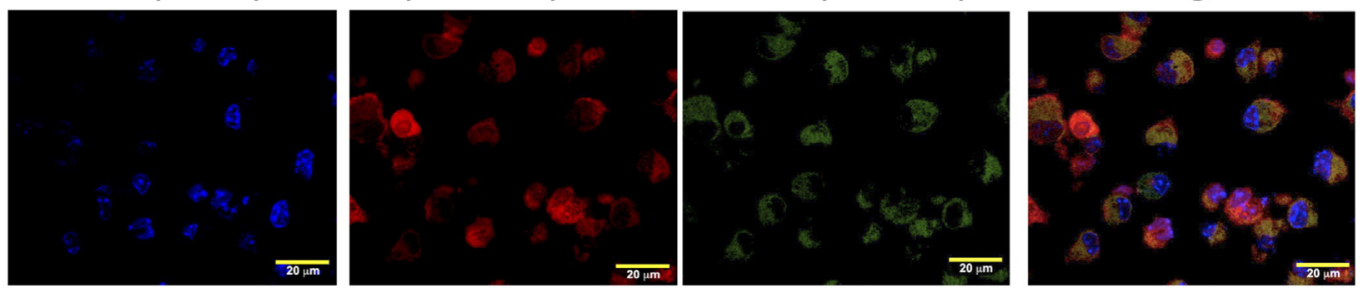

C
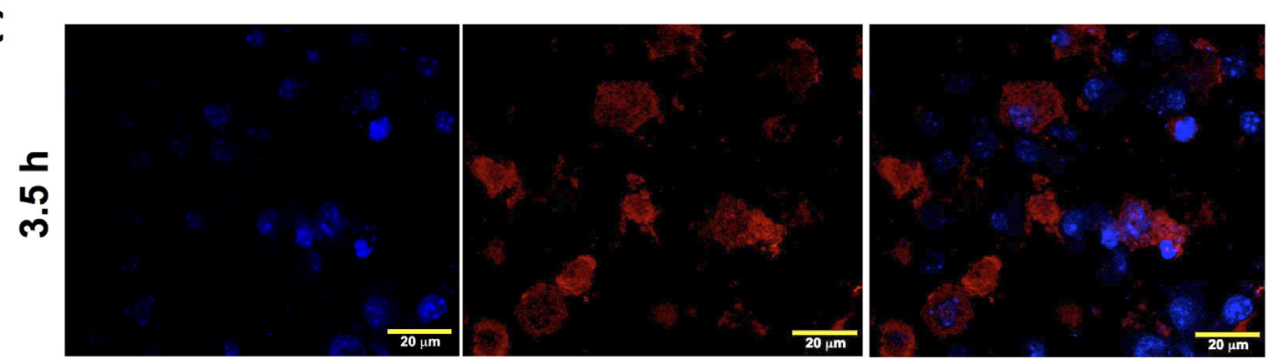

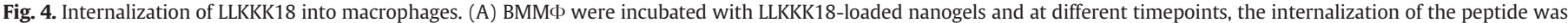

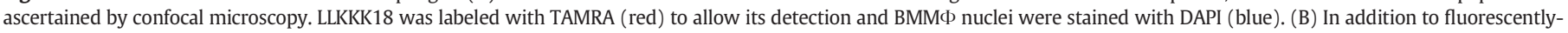

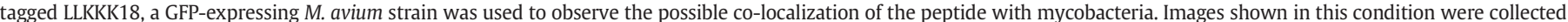

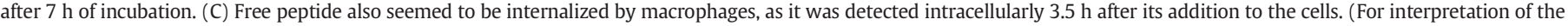
references to color in this figure legend, the reader is referred to the web version of this article.)

To further understand the extent of peptide internalization and its fate inside the cell, this was further analyzed and quantified through mass spectrometry (MS). MS spectra allowed the identification of LLKKK18 collected from lysed macrophages (Fig. 5A). The percentage of intact peptide found within the macrophages was estimated by comparing its peak area $(m / z=2783.5)$ with the peak area obtained for a known amount of a bi-deuterated standard peptide $(m / z=2791.5)$, added after cell lysis.
Contrarily to what would be expected from the microscopy images, we observed no significant differences between the amount of internalized intact LLKKK18 after 3.5 and $7 \mathrm{~h}$ of incubation. Noteworthy, at $7 \mathrm{~h}$ MS spectra show some peaks with lower $m / z$ than the intact peptide, suggesting the presence of smaller peptide fragments (Fig. SI-1). Twenty-four hours after addition of the loaded nanogels only small traces of peptide were found inside macrophages. MS spectra also indicated that free peptide enters BMMФ. However, also in this case, the peaks 


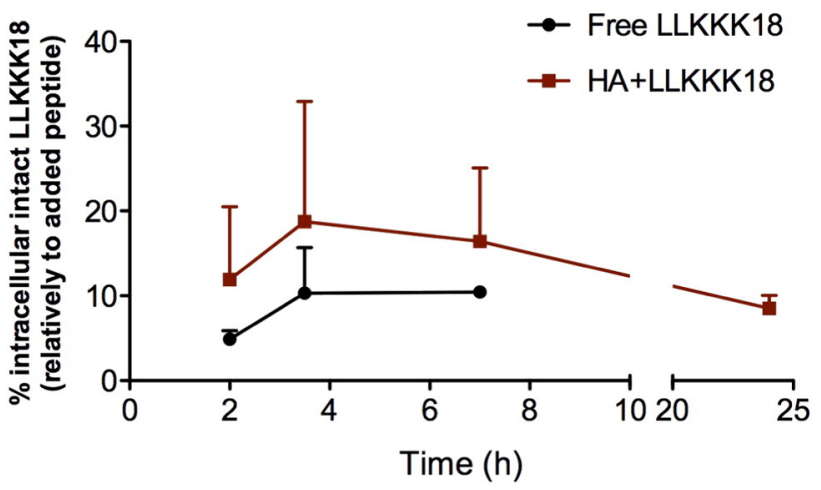

Fig. 5. Quantification of intracellular intact peptide. ВММФ were incubated in the presence of a biotinylated version of the peptide, comprising an isotope tag of four nondeuterated glycines $\left(\left[{ }^{1} \mathrm{H}\right]\right.$ LLKKK18). These were added to cells either in a free form or loaded into HA nanogels for different time periods. 1 pmol of an internal standard, consisting of the peptide with four bi-deuterated glycines $\left(\left[{ }^{2} \mathrm{H}\right]\right.$ LLKKK18) was added after cell lysis. The percentage of intact LLKKK18 present intracellularly at each timepoint was calculated from the area ratio obtained from the area of the peaks of the $[\mathrm{M}+\mathrm{H}]^{+}$signals (including all isotopes) of intact $\left[{ }^{1} \mathrm{H}\right]$ LLKKK18 and $\left[{ }^{2} \mathrm{H}\right]$ LLKKK18.

detected at low $m / z$ in the MS spectra suggest that most of this peptide is rapidly degraded inside macrophages.

\subsection{LLKKK18 effect on pro-inflammatory cytokines expression}

Cathelicidins like LL37 and its analogues have been associated with immunomodulatory properties [50]. Here we analyzed the effects on the expression of two cytokines, IL- 6 and TNF- $\alpha$, which play a key role in the immune response to infection. IL-6 expression was increased in the control (non-treated) ВMМФ $24 \mathrm{~h}$ after infection with $M$. tuberculosis (Fig. 6A). The expression of this cytokine then decreased over time up to $72 \mathrm{~h}$. However, in the presence of the HA nanogels, IL-6 levels were significantly lower than in the control at $24 \mathrm{~h}$. A further reduction in this cytokine expression to non-detectable levels was induced by the presence of LLKKK18. In fact, IL-6 expression is not detected at any time point in the presence of the peptide, similarly to what is observed in non-infected ВММФ.

Similarly, no TNF- $\alpha$ expression was identified at any timepoint or at any condition in the non-infected cells (Fig. 6B). Also in accordance with the IL- 6 results, the nanogel containing the peptide induced a significant decrease in TNF- $\alpha$ levels over time to almost basal values. However, it appears that the HA nanogel stimulated an increase of this cytokine, being statistically significant compared to the untreated control, at $24 \mathrm{~h}$.

\subsection{Peptide-loaded nanogel action on M. tuberculosis}

Fig. 7A shows that free LLKKK18 leads to a dose-dependent reduction of $M$. tuberculosis load growing in axenic cultures. The Minimum
Inhibitory Concentration $\left(\mathrm{MIC}_{50}\right)$, i.e. the peptide concentration resulting in a $50 \%$ mycobacteria growth reduction, was estimated to be $49.23 \pm 5.44 \mu \mathrm{M}$, slightly lower than the one previously obtained for M. avium $2447(58.81 \pm 0.07 \mu \mathrm{M})$ [26]. Once again, these values (corresponding to about $114 \mu \mathrm{g} / \mathrm{ml}$ ) are higher than the ones previously reported for conventional antibiotics against M. tuberculosis: 0.025$0.05 \mu \mathrm{g} / \mathrm{ml}$ for isoniazid, $<100 \mu \mathrm{g} / \mathrm{ml}$ for pyrazinamide, $0.06-0.25 \mu \mathrm{g} /$ $\mathrm{ml}$ for rifampicin and $0.94-3.8 \mu \mathrm{g} / \mathrm{ml}$ for ethambutol [46]. However, higher MIC values have been reported for other peptides. For example, MIC values of 300 and $1200 \mu \mathrm{g} / \mathrm{ml}$ have been reported for MIAP and Magainin-1, respectively [51]. Azurocidin has been reported to kill 55\% of M. tuberculosis H37Rv at $100 \mu \mathrm{g} / \mathrm{ml}$ [52]. Also, the M(LLKK) ${ }_{2} \mathrm{M}$ peptide series presented a MIC of $125 \mu \mathrm{g} / \mathrm{ml}$ [16].

Also in a similar fashion to what occurred with M. avium strains, $100 \mu \mathrm{M}$ LLKKK18-loaded nanogel reduced $(\sim 1.5 \log )$ the M. tuberculosis load within infected BMMФ (Fig. 7B). Moreover, treatment of $M$. tuberculosis-infected mice with the peptide-containing nanogel resulted in a significant effect of LLKKK18 against these pathogenic mycobacteria (Fig. 7C). Two different therapy regimens were tested, comprising either 5 or 10 administrations of the peptide-nanogel formulations, administrated every other day. Results in Fig. 7C show that the shorter therapy with the nanogel alone induced a decrease in mycobacteria levels, whereas this effect disappears for a longer administration regimen. Nevertheless, the shorter peptide-nanogel regimen led to a 0.7$\log$ reduction in mycobacteria levels, significantly different from the nanogel alone. This effect was further augmented to $~ 1.2-\log$ decrease $(p<0.01)$ by doubling the number of administrations.

Histology sections of the lung tissues do not show any visible differences between the different treatment conditions (HA alone and peptide-loaded nanogel) in terms of lesion extent and severity, although there seems to be an improvement regarding the number and size of granulomas relatively to the non-treated tissues (Fig. 8).

\section{Discussion}

Despite the plethora of applications provided by antimicrobial peptides, their use in the biomedical field is often disregarded due to toxicity, stability and solubility issues [53]. In the present work, we encapsulated the LL37's analogue LLKKK18 in self-assembling HA nanogels previously developed by our group [29]. This loading resulted in increased average particle size and neutralization of the HA anionic charge. The cationicity and hydrophobicity of the peptide may act as a driving force leading to its encapsulation within the hydrophobic core of the negatively charged nanogel. Such encapsulation may, at least partially, account for the increase in the average diameter of the particles, as a similar event has been reported with insulin-loaded poly(lactideco-glycolide) nanoparticles [54]. On the other hand, it is possible that the increase in particle size upon peptide loading reflects the formation of self-assembling macromolecular micelles. Although they might undergo extrusion upon filtration, they re-assemble afterwards to reach
A

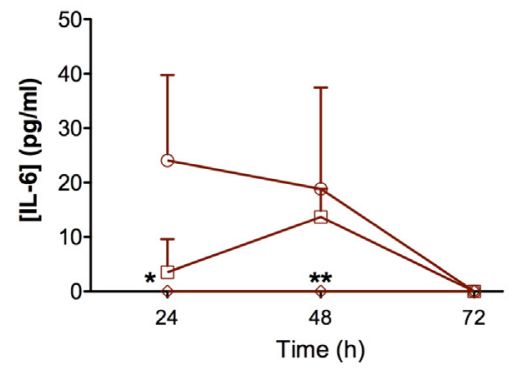

\section{B}

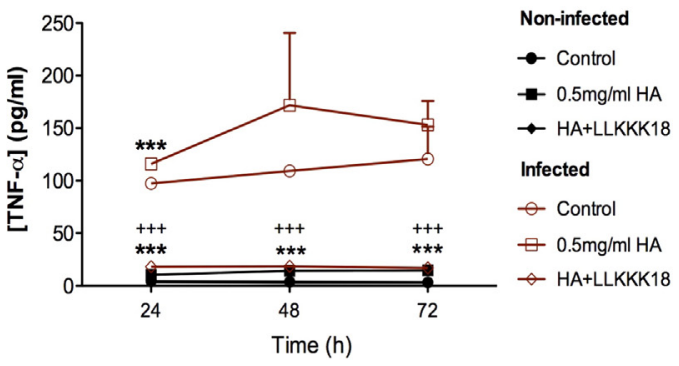

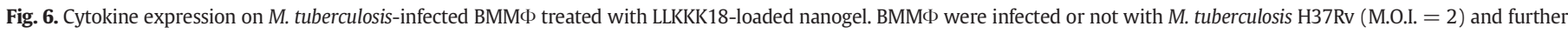

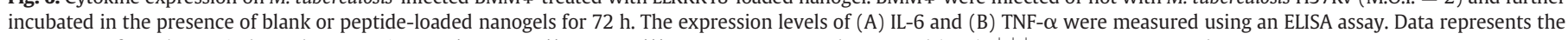
mean $\pm \mathrm{SD}$, for at least 3 independent experiments. ${ }^{*} p<0.05,{ }^{* *} p<0.01,{ }^{* * *} p<0.001$, compared to control (PBS). ${ }^{+++} p<0.001$, compared to HA. 

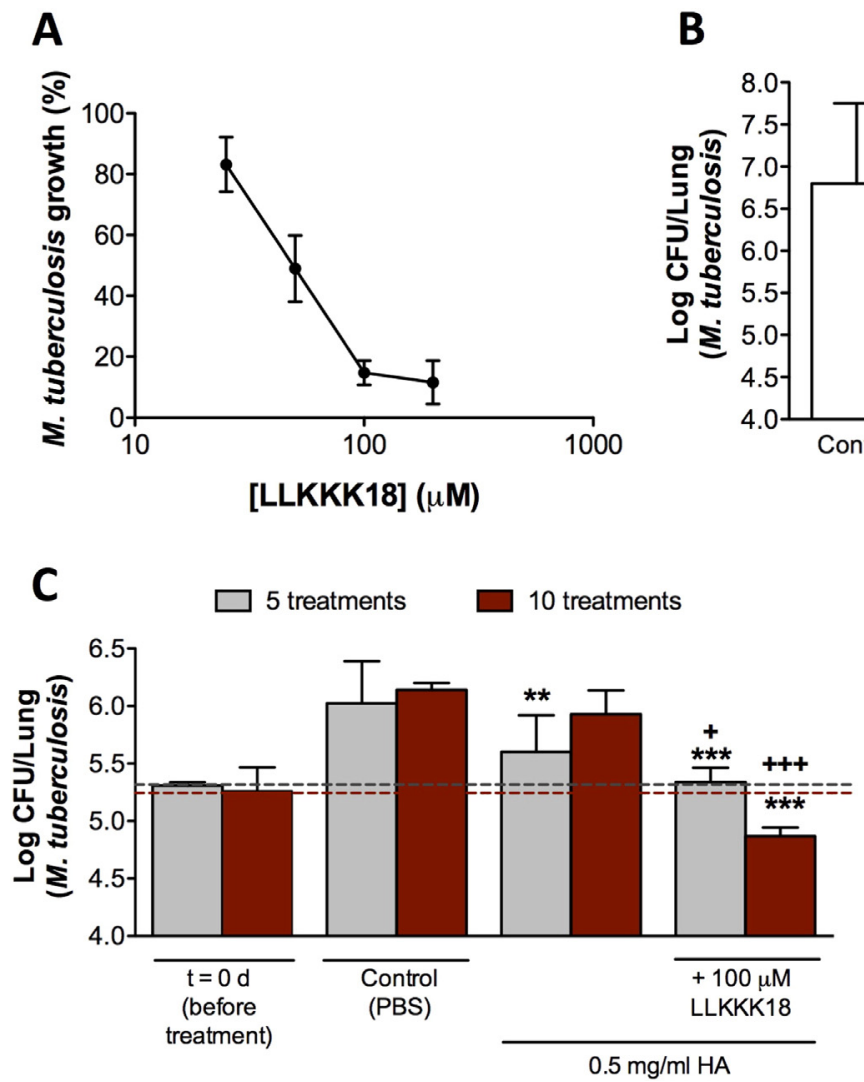

B

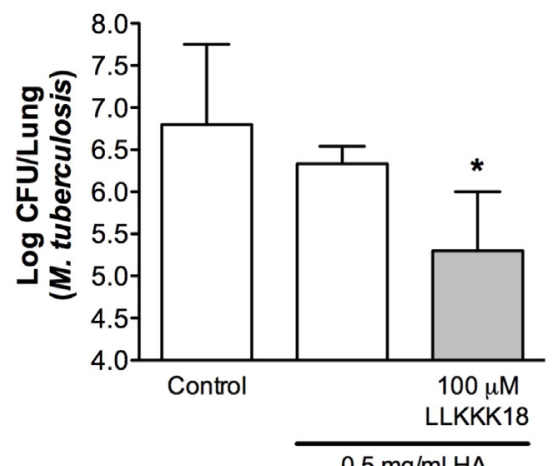

$0.5 \mathrm{mg} / \mathrm{ml} \mathrm{HA}$

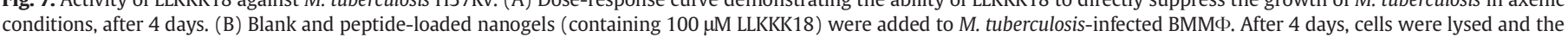

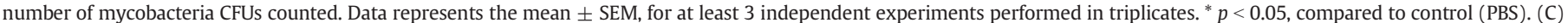

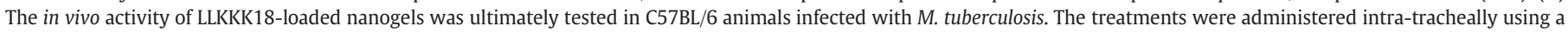

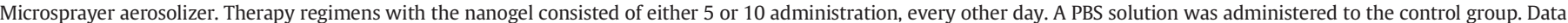

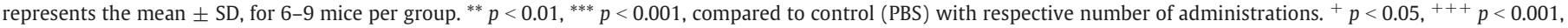
compared to HA with respective number of administrations.

an equilibrium state at a particle size of $500 \mathrm{~nm}$. Nevertheless, it should be noted that this is a highly reproducible process, as indicated by the small error bars and low polydispersity index $(0.1 \pm 0.1)$. The neutralization of the net electrical charge produced by the peptide suggests the binding of LLKKK18 to the surface of the nanogel. Altogether, peptide-induced modifications may be advantageous, as uptake by macrophages is enhanced for particles larger than $0.5 \mu \mathrm{m}[55,56]$, and charge neutralization may decrease the nanogels cytotoxicity (known to increase in the presence of charged - especially anionic - nanoparticles) [57,58]. Moreover, the particles size distribution becomes monomodal in the presence of the peptide, resulting in more homogeneous emulsions.

Nagaoka and colleagues [59] reported the toxicity of free LLKKK18 in peritoneal macrophages and RAW 264.7 cells at concentrations above $10 \mu \mathrm{g} / \mathrm{ml}$ (approximately $4.3 \mu \mathrm{M}$ ). Indeed, here we showed that a similar concentration $(5 \mu \mathrm{M})$ of free peptide reduced the viability of bone marrow-derived macrophages in $21-26 \%$ and that at $100 \mu \mathrm{M}$, almost all cells were non-viable. However, we also demonstrated that LLKKK18 loaded into the nanogel displayed no cytotoxic effects, in terms of intracellular esterase activity and plasma membrane integrity, up to $100 \mu \mathrm{M}$ (more than 23-fold the toxic concentration reported for free peptide). This is a relevant result, as we clearly show that peptide loading into the HA nanogels overcomes one of the major problems associated with the exogenous administration of these peptides.

Up to this concentration, the total number of apoptotic cells also remained at basal levels. Nevertheless, a slight nitric oxide production was observed in the presence of the peptide. Indeed, reactive nitrogen species (RNS), like $\cdot \mathrm{NO}$, are usually produced by macrophages as a way of eliminating invading bacteria [44], suggesting that this $\bullet \mathrm{NO}$ induction by the peptide may contribute to the increased mycobactericidal activity.

Taken together, the modifications in particle size, charge and cytotoxicity proved important to facilitate the intracellular delivery of the peptide to macrophages. Although the uptake of HA should not be expected from macrophages in normal physiological conditions, we observed that infected macrophages successfully internalized this nanogel. The overexpression of the CD44 receptor by activated macrophages, previously reported by Underhill and co-workers [31], might positively influence the nanogel uptake. Most importantly, the nanogel facilitated the peptide targeting to mycobacteria residing within intracellular compartments. Such targeting assumes great relevance considering the modifications in vacuolar trafficking that allow the masking of mycobacteria within macrophages [6] and potentiates a direct killing mechanism. The detection of both peptide and mycobacteria throughout the cytoplasm suggests that the co-localization of peptide with mycobacteria may be non-specific. However, additional experiments will be required to find any co-localization in specific intracellular compartments.

Most importantly, in vitro incubation of macrophages with LLKKK18-loaded nanogel reduced the intracellular levels of both $M$. avium and $M$. tuberculosis. These results strengthen the importance of using a proper carrier to deliver anti-TB drugs. Indeed, despite its uptake by cultured macrophages, free LLKKK18 failed to reach mycobacteria and reduce infection levels, which is in accordance with previous work regarding the induction of intracellular overexpression of its murine counterpart cRAMP [26]. 

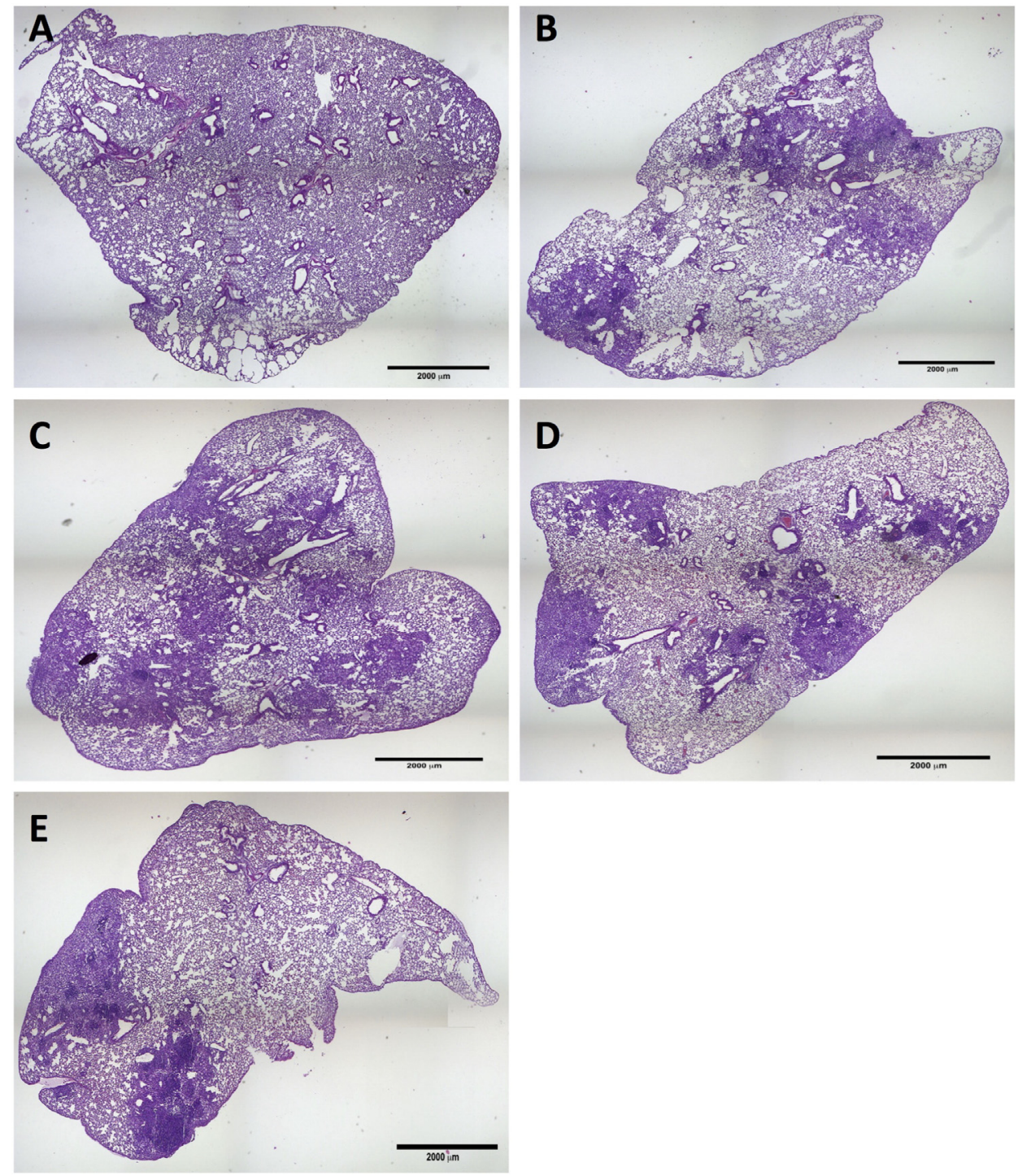

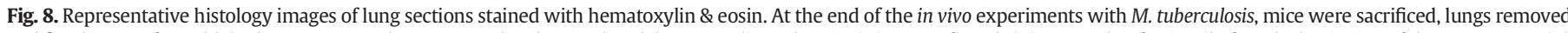

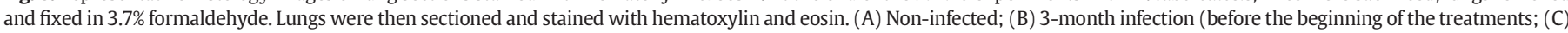
PBS, 10 administrations; (D) HA nanogels, 10 administrations; (E) LLKKK18-loaded nanogels, 10 administrations.

Compared with data reported in the literature for other drugs, in particular standard antibiotics, the concentration of LLKKK18 herein reported to inhibit $50 \%$ of mycobacteria growth may be considered high. However, is not uncommon to find some variability among MIC values for a drug against the same mycobacterial strain. This is the case of rifampicin, whose MIC against M. avium may range from $0.03 \mu \mathrm{g} / \mathrm{ml}[60]$ to $0.5 \mu \mathrm{g} /$ $\mathrm{ml}$ [61]. Differences in terms of methodologies may account for this variability and include: 1 ) the use of different strains (some are more susceptible/resistant than others); 2) the method used to determine the MIC (e.g. resazurin, which gives an indication of the cells metabolic activity vs CFU counting, which correlates with total bacteria number); 3 ) testing conditions (e.g. initial inoculum, culture media, incubation period). This variability is further noticed in in vivo testing. Parameters like administration route, dose regimen (concentration and frequency), period post-infection or initial inoculum greatly influence the outcome of infection and make it difficult to compare different studies.

It is also relevant noting that diminished levels of two pro-inflammatory cytokines, IL- 6 and TNF- $\alpha$, accompanied the decrease of $M$. tuberculosis load in infected macrophages treated with HA + LLKKK18. IL-6, in particular, may be considered a potent biomarker of mycobacterial infection due to its in vitro overexpression in mycobacteria-infected cells [62]. Moreover, our data on TNF- $\alpha$ expression is consistent with previous findings using LL37 [63] and further support the modulation of macrophages response to infection by cathelicidins. Considering the key role of these two cytokines in stimulating the immune response during infection $[64,65]$, a decrease in their expression levels may indeed be associated with the reduced mycobacterial load within macrophages.

It has been long known that results obtained in vitro for anti-TB drugs may not exactly match their efficacy in vivo [66,67]. This was not the case with LLKKK18-loaded nanogel, as the peptide induced a significant decrease of the mycobacterial burden in mice infected with mycobacteria of different virulence and pathogenicity.

Some discrepancies were observed regarding the mycobactericidal activity against the two M. avium strains tested, with a higher effect during M. avium 2447 infection. The growth of this strain is arrested as a result of both innate and adaptive immune mechanisms whereas $M$. avium 25291, known for its higher virulence, continues to proliferate until it eventually kills the animal [68,69]. In view of the fact that one of the major issues related with the failure of some anti-TB drugs, including the standard antibiotic isoniazid, is their inefficacy against mycobacteria in stationary phase or with very low proliferating rates [70], these results are unexpected. Two different hypothesis may help explain such findings: 1) M. avium 25291 may be more resistant to the peptide; 2 ) despite same inoculum and peptide concentration 
were used, the every other day therapy regimen gives time for the mycobacteria that are not eliminated to continue proliferating. In this sense, it is reasonable to expect only a slight reduction of M. avium 25291 burden.

Most importantly, a significant reduction in mycobacterial levels was found in the lungs of mice infected with $M$. tuberculosis after treatment with peptide-loaded nanogel. This effect appeared to be dose-dependent, as doubling the number of administrations resulted in a more pronounced reduction of the bacterial load, reaching levels below the ones observed before the beginning of the treatment. Of note, administration of empty HA nanogels also reduced the infection levels in mice infected with either M. tuberculosis (only after 5 doses of HA) or M. avium 25291. This is not completely unexpected, as the CD44 receptor has been reported to mediate the entry of mycobacteria into macrophages [71]. The interaction of HA with CD44 receptors may thus block the entry of newly proliferating bacteria or prevent the activation of pathways that may lead to the induction of residing mycobacteria proliferation, in similar fashion to what has been described in Listeria monocytogenes [72].

Although MIC values obtained in axenic conditions may not be considered very impressive, the observed LLKKK18-induced reduction of the mycobacterial load in infected macrophages and in infected animals is of great relevance. Achieving a $\sim 1.2-\log$ reduction in $M$. tuberculosis levels in the lungs of infected mice is per se an important result, considering that: the peptide-loaded nanogels were administered only 10 times (every other day); and the therapy comprised a single bioactive molecule, contrasting with the standard multiple drug regimens. De Groote and co-workers [41] evaluated the outcome of the 6-month standard drug regimen of isoniazid, rifampicin and pyrazinamide. The authors showed that it takes that long period, with daily administrations of the three drugs combined, to achieve a complete elimination of the infection. Additionally, the authors showed that even after 6 months a combination of pyrazinamide and rifampicin only resulted in a 2-log reduction. Kalita et al. [73] reported the effect of a combined therapy of isoniazid and rifampicin, administered daily during 46 weeks, against $M$. tuberculosis. According to that study, when both drugs were administered at $12.5 \mathrm{mg} / \mathrm{kg} /$ day, using the referred therapy regimen, less than 1-log reduction was attained. Doubling of both drugs concentration to $25 \mathrm{mg} / \mathrm{kg} /$ day only resulted in an overall reduction of mycobacterial load in mice lungs of about 1.5-log.

Having attained such an effect with LLKKK18 in particular is even more relevant taking into consideration that previous experiments comprising the induction of intracellular overexpression of LL37 (LLKKK18's "parent" peptide) failed to eliminate mycobacteria within host macrophages, as it was rapidly cleared from the intracellular milieu [26].

Moreover, it is reasonable to expect that optimization of the formulation may result in higher efficacy, while reducing peptide concentration and dosage regimen. Such optimization will be important to reduce the costs of production, which are currently higher than the \$19-22 required for a standard antibiotic therapy of 6 months [11]. Nevertheless, costs associated with the 24-month, multiple antibiotic therapies required for the treatment of multidrug-resistant tuberculosis remain elevated (ranging between $\$ 4000-6000$ ). Although further studies need to be performed, given the lower probability of mycobacteria acquiring resistance to AMPs as compared to antibiotics, due to their non-specific killing mechanism [18,19], these LLKKK18-loaded nanogels may assume particular interest for the treatment of multidrug- (MDR) or extremely drugresistant (XDR) forms of tuberculosis, as well as atypical mycobacterioses showing resistance to conventional therapies.

\section{Conclusions}

Administration of LLKKK18 loaded into self-assembling hyaluronic acid nanogels holds promising indications as a novel method to treat mycobacterial infections. The nanogel target the peptide towards the main infected sites, while boosting its potential by: 1) allowing the use of high therapeutic doses; 2) facilitating peptide uptake by infected macrophages; 3) stabilizing the peptide within their hydrophobic core; and 4 ) reducing proteolytic degradation.

Long-term and expensive standard therapies based on multiple drug cocktails often result in low patient compliance, with subsequent emergence of multidrug-resistant strains and proliferation of the disease. Our data thus suggest that LLKKK18-loaded nanogel may hold great potential as an alternative approach to control tuberculosis and other mycobacterioses, finding particular interest for treatment of antibioticresistant forms.

\section{Disclosure}

The authors declare no conflicts of interest.

\section{Acknowledgements}

This study was supported by the Portuguese Foundation for Science and Technology (FCT) under the scope of the strategic funding of UID/ BIO/04469/2013 unit and COMPETE 2020 (POCI-01-0145-FEDER006684). The authors also acknowledge the Project RECI/BBB-EBI/0179/ 2012 (FCOMP-01-0124-FEDER-027462). The authors thank Dr. Hugo Osório (Proteomics Lab at I3S - Institute for Health Research and Innovation, Porto, Portugal) for the MALDI-ToF analysis. JPS acknowledges FCT for the financial support provided by grant SFRH/BPD/64958/2010.

\section{Appendix A. Supplementary data}

Supplementary data to this article can be found online at http://dx. doi.org/10.1016/j.jconrel.2016.05.064.

\section{References}

[1] World Health Organization (WHO), Global Tuberculosis Report, 2015.

[2] E.A. Kendall, M.O. Fofana, D.W. Dowdy, Burden of transmitted multidrug resistance in epidemics of tuberculosis: a transmission modelling analysis, Lancet Respir. Med. 3 (2015) 963-972.

[3] K. Dheda, C.E. Barry 3rd, G. Maartens, Tuberculosis, Lancet (2016), http://dx.doi.org/ 10.1016/S0140-6736(15)00151-8.

[4] R. Appelberg, Pathogenesis of Mycobacterium avium infection: typical responses to an atypical mycobacterium? Immunol. Res. 35 (2006) 179-190.

[5] G. Griffiths, B. Nystrom, S.B. Sable, G.K. Khuller, Nanobead-based interventions for the treatment and prevention of tuberculosis, Nat. Rev. Microbiol. 8 (2010) 827-834.

[6] R.A. Fratti, J. Chua, I. Vergne, V. Deretic, Mycobacterium tuberculosis glycosylated phosphatidylinositol causes phagosome maturation arrest, Proc. Natl. Acad. Sci. U. S. A. 100 (2003) 5437-5442.

[7] A.J. Hickey, P.G. Durham, A. Dharmadhikari, E.A. Nardell, Inhaled drug treatment for tuberculosis: past progress and future prospects, J. Control. Release (2015), http:// dx.doi.org/10.1016/j.jconrel.2015.11.018.

[8] A. Roy, M. Eisenhut, R.J. Harris, L.C. Rodrigues, S. Sridhar, S. Habermann, L. Snell, P. Mangtani, I. Adetifa, A. Lalvani, I. Abubakar, Effect of BCG vaccination against Mycobacterium tuberculosis infection in children: systematic review and meta-analysis, BMJ 349 (2014) g4643.

[9] C. Nimmo, M. Lipman, P.P. Phillips, T. McHugh, A. Nunn, I. Abubakar, Shortening treatment of tuberculosis: lessons from fluoroquinolone trials, Lancet Infect. Dis. 15 (2015) 141-143.

[10] J.S. Mukherjee, M.L. Rich, A.R. Socci, J.K. Joseph, F.A. Viru, S.S. Shin, J.J. Furin, M.C. Becerra, D.J. Barry, J.Y. Kim, J. Bayona, P. Farmer, M.C. Smith Fawzi, K.J. Seung, Programmes and principles in treatment of multidrug-resistant tuberculosis, Lancet 363 (2004) 474-481.

[11] Médecins sans Frontières (MSF), MSF Access Campaign: DR-TB Drugs under the Microscope - Sources and Prices for Drug-Resistant Tuberculosis Medicines, 2012.

[12] A. Sosnik, Á.M. Carcaboso, R.J. Glisoni, M.A. Moretton, D.A. Chiappetta, New old challenges in tuberculosis: potentially effective nanotechnologies in drug delivery, Adv. Drug Deliv. Rev. 62 (2010) 547-559.

[13] A. Zumla, P. Nahid, S.T. Cole, Advances in the development of new tuberculosis drugs and treatment regimens, Nat. Rev. Drug Discov. 12 (2013) 388-404.

[14] N. Alsaad, B. Wilffert, R. van Altena, W.C. de Lange, T.S. van der Werf, J.G. Kosterink, J.W. Alffenaar, Potential antimicrobial agents for the treatment of multidrug-resistant tuberculosis, Eur. Resp. J. 43 (2014) 884-897.

[15] B. Prideaux, L.E. Via, M.D. Zimmerman, S. Eum, J. Sarathy, P. O'Brien, C. Chen, F. Kaya, D.M. Weiner, P.-Y. Chen, T. Song, M. Lee, T.S. Shim, J.S. Cho, W. Kim, S.N. Cho, K.N. Olivier, C.E. Barry Iii, V. Dartois, The association between sterilizing activity and drug distribution into tuberculosis lesions, Nat. Med. 21 (2015) 1223-1227.

[16] J.S. Khara, Y. Wang, X.-Y. Ke, S. Liu, S.M. Newton, P.R. Langford, Y.Y. Yang, P.L.R. Ee, Anti-mycobacterial activities of synthetic cationic $\alpha$-helical peptides and their synergism with rifampicin, Biomaterials 35 (2014) 2032-2038. 
[17] A. Padhi, M. Sengupta, S. Sengupta, K.H. Roehm, A. Sonawane, Antimicrobial peptides and proteins in mycobacterial therapy: current status and future prospects, Tuberculosis 94 (2014) 363-373.

[18] R.E.W. Hancock, H.G. Sahl, Antimicrobial and host-defense peptides as new anti-infective therapeutic strategies, Nat. Biotechnol. 24 (2006) 1551-1557.

[19] K. Yamasaki, R.L. Gallo, Antimicrobial peptides in human skin disease, Eur. J. Dermatol. 18 (2008) 11-21.

[20] V. Nizet, Antimicrobial peptide resistance mechanisms of human bacterial pathogens, Curr. Issues Mol. Biol. 8 (2006) 11-26.

[21] A. Peschel, H.G. Sahl, The co-evolution of host cationic antimicrobial peptides and microbial resistance, Nat. Rev. Microbiol. 4 (2006) 529-536.

[22] B. Rivas-Santiago, R. Hernandez-Pando, C. Carranza, E. Juarez, J.L. Contreras, D. Aguilar-Leon, M. Torres, E. Sada, Expression of cathelicidin LL-37 during Mycobacterium tuberculosis infection in human alveolar macrophages, monocytes, neutrophils, and epithelial cells, Infect. Immun. 76 (2008) 935-941.

[23] A. Mily, R.S. Rekha, S.M.M. Kamal, E. Akhtar, P. Sarker, Z. Rahim, G.H. Gudmundsson, B. Agerberth, R. Raqib, Oral intake of phenylbutyrate with or without vitamin d-3 upregulates the cathelicidin LL-37 in human macrophages: a dose finding study for treatment of tuberculosis, BMC Pulm. Med. 13 (2013) 23-30.

[24] C.D. Ciornei, T. Sigurdardottir, A. Schmidtchen, M. Bodelsson, Antimicrobial and chemoattractant activity, lipopolysaccharide neutralization, cytotoxicity, and inhibition by serum of analogs of human cathelicidin LL-37, Antimicrob. Agents Chemother. 49 (2005) 2845-2850.

[25] I. Nagaoka, K. Kuwahara-Arai, H. Tamura, K. Hiramatsu, M. Hirata, Augmentation of the bactericidal activities of human cathelicidin cap18/1-37-derived antimicrobial peptides by amino acid substitutions, Inflamm. Res. 54 (2005) 66-73.

[26] J.C. Santos, S. Silva-Gomes, J.P. Silva, F.M. Gama, G. Rosa, R.L. Gallo, R. Appelberg, Endogenous cathelicidin production limits inflammation and protective immunity to mycobacterium avium in mice, Immunol. Infect. Dis. 2 (2014) 1-12.

[27] M.M. Gaspar, A. Cruz, A.G. Fraga, A.G. Castro, M.E. Cruz, J. Pedrosa, Developments on drug delivery systems for the treatment of mycobacterial infections, Curr. Top. Med. Chem. 8 (2008) 579-591.

[28] L. Bi, L. Yang, G. Narsimhan, A.K. Bhunia, Y. Yao, Designing carbohydrate nanoparticles for prolonged efficacy of antimicrobial peptide, J. Control. Release 150 (2011) 150-156.

[29] S.S. Pedrosa, C. Goncalves, L. David, M. Gama, A novel crosslinked hyaluronic acid nanogel for drug delivery, Macromol. Biosci. 14 (2014) 1556-1568.

[30] Z. Sladek, D. Rysanek, Expression of macrophage CD44 receptor in the course of experimental inflammatory response of bovine mammary gland induced by lipopolysaccharide and muramyl dipeptide, Res. Vet. Sci. 86 (2009) 235-240.

[31] C.B. Underhill, H.A. Nguyen, M. Shizari, M. Culty, CD44 positive macrophages take up hyaluronan during lung development, Dev. Biol. 155 (1993) 324-336.

[32] Z. Grabarek, J. Gergely, Zero-length crosslinking procedure with the use of active esters, Anal. Biochem. 185 (1990) 131-135.

[33] W.J. Waddell, A simple ultraviolet spectrophotometric method for the determination of protein, J. Lab. Clin. Med. 48 (1956) 311-314.

[34] E. Torrado, A.G. Fraga, E. Logarinho, T.G. Martins, J.A. Carmona, J.B. Gama, M.A. Carvalho, F. Proenca, A.G. Castro, J. Pedrosa, IFN-gamma-dependent activation of macrophages during experimental infections by Mycobacterium ulcerans is impaired by the toxin mycolactone, J. Immunol. 184 (2010) 947-955.

[35] J.P. Silva, M.F. Proença, O.P. Coutinho, Protective role of new nitrogen compounds on ROS/RNS-mediated damage to PC12 cells, Free Radic. Res. 42 (2008) 57-69.

[36] D. Tsikas, Analysis of nitrite and nitrate in biological fluids by assays based on the griess reaction: appraisal of the griess reaction in the L-arginine/nitric oxide area of research, J. Chromatogr. B 851 (2007) 51-70.

[37] A.E. Parker, L.E. Bermudez, Expression of the green fluorescent protein (GFP) in Mycobacterium avium as a tool to study the interaction between mycobacteria and host cells, Microb. Pathog. 22 (1997) 193-198.

[38] M.S. Gomes, S. Sousa Fernandes, J.V. Cordeiro, S. Silva Gomes, A. Vieira, R. Appelberg, Engagement of toll-like receptor 2 in mouse macrophages infected with mycobacterium avium induces non-oxidative and tnf-independent anti-mycobacterial activity, Eur. J. Immunol. 38 (2008) 2180-2189.

[39] F. Burlina, S. Sagan, G. Bolbach, G. Chassaing, A direct approach to quantification of the cellular uptake of cell-penetrating peptides using maldi-tof mass spectrometry, Nat. Protoc. 1 (2006) 200-205.

[40] A. Cruz, A.G. Fraga, J.J. Fountain, J. Rangel-Moreno, E. Torrado, M. Saraiva, D.R. Pereira, T.D. Randall, J. Pedrosa, A.M. Cooper, A.G. Castro, Pathological role of interleukin 17 in mice subjected to repeated bcg vaccination after infection with $\mathrm{Myco}$ bacterium tuberculosis, J. Exp. Med. 207 (2010) 1609-1616.

[41] M.A. De Groote, J.C. Gilliland, C.L. Wells, E.J. Brooks, L.K. Woolhiser, V. Gruppo, C.A. Peloquin, I.M. Orme, A.J. Lenaerts, Comparative studies evaluating mouse models used for efficacy testing of experimental drugs against Mycobacterium tuberculosis, Antimicrob. Agents Chemother. 55 (2011) 1237-1247.

[42] M. Bivas-Benita, R. Zwier, H.E. Junginger, G. Borchard, Non-invasive pulmonary aerosol delivery in mice by the endotracheal route, Eur. J. Pharm. Biopharm. 61 (2005) 214-218.

[43] S. Mohanty, P. Jena, R. Mehta, R. Pati, B. Banerjee, S. Patil, A. Sonawane, Cationic antimicrobial peptides and biogenic silver nanoparticles kill mycobacteria without eliciting DNA damage and cytotoxicity in mouse macrophages, Antimicrob. Agents Chemother. 57 (2013) 3688-3698.

[44] M. Valko, D. Leibfritz, J. Moncol, M.T.D. Cronin, M. Mazur, J. Telser, Free radicals and antioxidants in normal physiological functions and human disease, Int. J. Biochem. Cell Biol. 39 (2007) 44-84.

[45] S. Pfeiffer, A. Lass, K. Schmidt, B. Mayer, Protein tyrosine nitration in mouse peritoneal macrophages activated in vitro and in vivo: evidence against an essential role of peroxynitrite, FASEB J. 15 (2001) 2355-2364.
[46] L. Heifets, Susceptibility testing of mycobacterium avium complex isolates, Antimicrob. Agents Chemother. 40 (1996) 1759-1767.

[47] C. Andrejak, D.V. Almeida, S. Tyagi, P.J. Converse, N.C. Ammerman, J.H. Grosset, Characterization of mouse models of Mycobacterium avium complex infection and evaluation of drug combinations, Antimicrob. Agents Chemother. 59 (2015) 2129-2135.

[48] L.E. Bermudez, N. Motamedi, P. Kolonoski, C. Chee, G. Baimukanova, R. Bildfell, G. Wang, L.T. Phan, S.Y. Lowell, The efficacy of clarithromycin and the bicyclolide EDP-420 against Mycobacterium avium in a mouse model of pulmonary infection, J. Infect. Dis. 197 (2008) 1506-1510.

[49] S. Roque, C. Nobrega, R. Appelberg, M. Correia-Neves, IL-10 underlies distinct susceptibility of balb/c and C57BL/6 mice to Mycobacterium avium infection and influences efficacy of antibiotic therapy, J. Immunol. 178 (2007) 8028-8035.

[50] J.P. Silva, S. Dhall, M. Garcia, A. Chan, C. Costa, M. Gama, M. Martins-Green, Improved burn wound healing by the antimicrobial peptide LLKKK18 released from conjugates with dextrin embedded in a carbopol gel, Acta Biomater. 26 (2015) 249-262.

[51] P. Santos, A. Gordillo, L. Osses, L.M. Salazar, C.Y. Soto, Effect of antimicrobial peptides on atpase activity and proton pumping in plasma membrane vesicles obtained from mycobacteria, Peptides 36 (2012) 121-128.

[52] P. Jena, S. Mohanty, T. Mohanty, S. Kallert, M. Morgelin, T. Lindstrom, N. Borregaard, S. Stenger, A. Sonawane, O.E. Sorensen, Azurophil granule proteins constitute the major mycobactericidal proteins in human neutrophils and enhance the killing of mycobacteria in macrophages, PLoS One 7 (2012), e50345.

[53] H. Kim, J.H. Jang, S.C. Kim, J.H. Cho, De novo generation of short antimicrobial peptides with enhanced stability and cell specificity, J. Antimicrob. Chemother. 69 (2014) 121-132.

[54] P.S. Kumar, S. Ramakrishna, T.R. Saini, P.V. Diwan, Influence of microencapsulation method and peptide loading on formulation of poly(lactide-co-glycolide) insulin nanoparticles, Pharmazie 61 (2006) 613-617.

[55] R. Pandey, G.K. Khuller, Antitubercular inhaled therapy: opportunities, progress and challenges, J. Antimicrob. Chemother. 55 (2005) 430-435.

[56] J.A. Champion, A. Walker, S. Mitragotri, Role of particle size in phagocytosis of polymeric microspheres, Pharm. Res. 25 (2008) 1815-1821.

[57] N.M. Schaeublin, L.K. Braydich-Stolle, A.M. Schrand, J.M. Miller, J. Hutchison, J.J. Schlager, S.M. Hussain, Surface charge of gold nanoparticles mediates mechanism of toxicity, Nanoscale 3 (2011) 410-420.

[58] Y. Tomita, A. Rikimaru-Kaneko, K. Hashiguchi, S. Shirotake, Effect of anionic and cationic n-butylcyanoacrylate nanoparticles on $\mathrm{NO}$ and cytokine production in RAW264.7 cells, Immunopharm, Immunotoxicology 33 (2011) 730-737.

[59] I. Nagaoka, S. Hirota, F. Niyonsaba, M. Hirata, Y. Adachi, H. Tamura, S. Tanaka, D. Heumann, Augmentation of the lipopolysaccharide-neutralizing activities of human cathelicidin CAP18/LL-37-derived antimicrobial peptides by replacement with hydrophobic and cationic amino acid residues, Clin. Diagn. Lab. Immunol. 9 (2002) 972-982.

60] T. Gumbo, A. Louie, M.R. Deziel, W. Liu, L.M. Parsons, M. Salfinger, G.L. Drusano, Concentration-dependent Mycobacterium tuberculosis killing and prevention of resistance by rifampin, Antimicrob. Agents Chemother. 51 (2007) 3781-3788.

[61] J. Suo, C.E. Chang, T.P. Lin, L.B. Heifets, Minimal inhibitory concentrations of isoniazid, rifampin, ethambutol, and streptomycin against Mycobacterium tuberculosis strains isolated before treatment of patients in Taiwan, Am. Rev. Respir. Dis. 138 (1988) 999-1001.

[62] P.P. Singh, A. Goyal, Interleukin-6: a potent biomarker of mycobacterial infection, Springerplus 2 (2013) 686.

[63] F. Torres-Juarez, A. Cardenas-Vargas, A. Montoya-Rosales, I. Gonzalez-Curiel, M.H. Garcia-Hernandez, J.A. Enciso-Moreno, R.E. Hancock, B. Rivas-Santiago, Ll-37 immunomodulatory activity during Mycobacterium tuberculosis infection in macrophages, Infect. Immun. 83 (2015) 4495-4503.

[64] A.N. Martinez, S. Mehra, D. Kaushal, Role of interleukin 6 in innate immunity to mycobacterium tuberculosis infection, J. Infect. Dis. 207 (2013) 1253-1261.

[65] A. Mootoo, E. Stylianou, M.A. Arias, R. Reljic, TNF-alpha in tuberculosis: a cytokine with a split personality, Inflamm. Allergy Drug Targets 8 (2009) 53-62.

[66] R.M. McCune, R. Tompsett, W. McDermott, The fate of Mycobacterium tuberculosis in mouse tissues as determined by the microbial enumeration technique. II. The conversion of tuberculous infection to the latent state by the administration of pyrazinamide and a companion drug, J. Exp. Med. 104 (1956) 763-802.

[67] J.D. McKinney, In vivo veritas: the search for TB drug targets goes live, Nat. Med. 6 (2000) 1330-1333.

[68] M. Flórido, A.S. Gonçalves, R.A. Silva, S. Ehlers, A.M. Cooper, R. Appelberg, Resistance of virulent Mycobacterium avium to gamma interferon-mediated antimicrobial activity suggests additional signals for induction of mycobacteriostasis, Infect. Immun. 67 (1999) 3610-3618.

[69] M. Borges, P. Barreira-Silva, M. Flórido, M.B. Jordan, M. Correia-Neves, R. Appelberg, Molecular and cellular mechanisms of Mycobacterium avium-induced thymic atrophy, J. Immunol. 189 (2012) 3600-3608.

[70] P. Onyebujoh, A. Zumla, I. Ribeiro, R. Rustomjee, P. Mwaba, M. Gomes, J.M. Grange Treatment of tuberculosis: present status and future prospects, Bull. World Health Organ. 83 (2005) 857-865.

[71] J.C. Leemans, S. Florquin, M. Heikens, S.T. Pals, R. van der Neut, T. van der Poll, CD44 is a macrophage binding site for Mycobacterium tuberculosis that mediates macrophage recruitment and protective immunity against tuberculosis, J. Clin. Invest. 111 (2003) 681-689.

[72] E. Eriksson, L. Dons, A.G. Rothfuchs, P. Heldin, H. Wigzell, M.E. Rottenberg, CD44-regulated intracellular proliferation of Listeria monocytogenes, Infect. Immun. 71 (2003) 4102-4111.

[73] A. Kalita, I. Verma, G.K. Khuller, Role of human neutrophil peptide-1 as a possible adjunct to antituberculosis chemotherapy, J. Infect. Dis. 190 (2004) 1476-1480. 